\title{
Pathophysiology of Exercise-Induced Muscle Damage and Its Structural, Functional, Metabolic, and Clinical Consequences
}

\author{
Andraž STOŽER ${ }^{1}$, Peter VODOPIVC ${ }^{1,2}$, Lidija KRIŽANČIĆ BOMBEK ${ }^{1}$ \\ ${ }^{1}$ Institute of Physiology, Faculty of Medicine, University of Maribor, Maribor, Slovenia, ${ }^{2}$ General \\ Hospital Murska Sobota, Rakičan, Slovenia
}

Received November 18, 2019

Accepted June 9, 2020

Epub Ahead of Print July 16, 2020

\section{Summary}

Extreme or unaccustomed eccentric exercise can cause exerciseinduced muscle damage, characterized by structural changes involving sarcomere, cytoskeletal, and membrane damage, with an increased permeability of sarcolemma for proteins. From a functional point of view, disrupted force transmission, altered calcium homeostasis, disruption of excitation-contraction coupling, as well as metabolic changes bring about loss of strength. Importantly, the trauma also invokes an inflammatory response and clinically presents itself by swelling, decreased range of motion, increased passive tension, soreness, and a transient decrease in insulin sensitivity. While being damaging and influencing heavily the ability to perform repeated bouts of exercise, changes produced by exercise-induced muscle damage seem to play a crucial role in myofibrillar adaptation. Additionally, eccentric exercise yields greater hypertrophy than isometric or concentric contractions and requires less in terms of metabolic energy and cardiovascular stress, making it especially suitable for the elderly and people with chronic diseases. This review focuses on our current knowledge of the mechanisms underlying exerciseinduced muscle damage, their dependence on genetic background, as well as their consequences at the structural, functional, metabolic, and clinical level. A comprehensive understanding of these is a prerequisite for proper inclusion of eccentric training in health promotion, rehabilitation, and performance enhancement.

\section{Key words}

Exercise $\bullet$ Eccentric $\bullet$ Muscle $\bullet$ Damage $\bullet$ Pathophysiology

\section{Corresponding author}

Andraž Stožer, Lidija Križančić Bombek, Institute of Physiology, Faculty of Medicine, University of Maribor, Taborska ulica 8, SI-2000 Maribor, Slovenia. E-mail: andraz.stozer@um.si, lidija.bombek@um.si

\section{Introduction}

In isometric exercise, the contracting muscle retains its length while producing force, in concentric exercise it shortens, and in eccentric or stretching exercise, it lengthens (Faulkner 2003). Isometric contractions serve to keep posture and hold loads, concentric contractions initiate movements, while eccentric contractions typically stop or decelerate them (Hoppeler 2016). If a person is unaccustomed to a specific exercise or if it is of greater than normal intensity or duration, all forms of exercise can cause damage and pain. However, exercise-induced muscle damage (EIMD) is most often caused by high intensity eccentric exercise (Proske and Morgan 2001). This is most probably because fewer motor units are recruited during eccentric exercise compared with other modes of contraction, resulting in a greater force per active motor unit and thus greater mechanical stress (Douglas et al. 2017a, Tee et al. 2007). In addition to mechanical stress, metabolic stress could also have a role in EIMD associated with eccentric exercise and is probably mostly responsible for cases of EIMD that occur with lower intensity endurance exercises where eccentric contraction is not the only or predominant mode of contraction, such as cycling and running (Tee et al. 2007). EIMD is characterized by several structural and functional changes at various organizational levels, which are the main topic of this review. At the cellular level, EIMD encompasses damage of myofibrils and Z-line streaming, membrane damage of T-tubules and sarcoplasmic reticulum, disrupted 
cytoskeletal organization, as well as changes in the action of glucose transport proteins, accompanied by changes in substrate levels. At the level of the whole organism, an increase in specific muscle proteins can be detected in plasma, whereas clinical examination reveals muscle soreness, swelling, decreased muscle strength and range of motion (Clarkson and Sayers 1999), as well as altered proprioception (Walsh et al. 2004). In preparation for this paper, we performed Pubmed and Embase searches for review articles using the following combination of keywords and operators "(exercise induced OR eccentric exercise) AND physiology AND muscle AND damage AND review". We analyzed in detail all articles dealing with key aforementioned etiopathogenetic events in exercise-induced muscle damage and their main consequences, ranging from the molecular to the systemic level, and included them in the bibliography. We also included further relevant review and research articles from within citation lists. Major, mechanistic, pioneering, and most recent articles were given most weight.

\section{Etiology and pathogenesis of EIMD}

\subsection{Sarcomere overstretch}

According to our current knowledge, the first step in the development of EIMD is stretching forcibly the myofibrils (sarcomeres in series) while they are contracting and thus disrupting their structure and organization, as first demonstrated by Friden and coworkers studying human muscle biopsies 40 years ago (Fridén et al. 1981, Proske and Allen 2005, Proske and Morgan 2001). More specifically, due to differences in length-tension relationships between individual sarcomeres, the weakest sarcomeres in a myofibril experience the largest proportion of length change. The reason for this might be that their actin-myosin overlap is further away from its optimum or their cross-sectional area is somewhat smaller at that moment than in other sarcomeres. If the length of the sarcomeres is already on the descending limb of their length-tension curves, as the myofilament overlap decreases further with progressive stretch, these sarcomeres become progressively weaker. They lengthen rapidly to a point with no myofilament overlap and therefore no active tension production. On the other hand, the tension in passive parallel elements in such "popped" sarcomeres increases and balances the active tension of adjacent sarcomeres, therefore halting further lengthening (Proske and Morgan 2001). Upon stretching out the muscle fiber, the next-weakest sarcomere overstretches and this process continues iteratively (Morgan 1990). When the muscle relaxes, myofilaments in the majority of overstretched sarcomeres re-interdigitate, but some fail to do so (Talbot and Morgan 1996). Regions with long sarcomere lengths before an active stretch contain the majority of disrupted sarcomeres after the stretch and the disrupted sarcomeres are longer than the rest. The number of disrupted sarcomeres presumably grows with repeated eccentric contractions (Proske and Morgan 2001). Since myofibrils are anchored to the membrane via the dystrophin complex (Gao and McNally 2015), overstretching the sarcomeres can also disrupt the anchoring structures, up to a point of membrane damage (Owens et al. 2019). This increases plasma membrane permeability and disrupts excitation-contraction coupling (ECC) (Macpherson et al. 1996). A concise illustration of the crucial events and their proposed temporal sequence in EIMD is given in Figure 1.

\subsection{Calcium homeostasis and impaired excitation- contraction coupling}

Membrane damage starts with a disruption of the T-tubule system, which negatively affects ECC. However, the fall in tension at this point is still reversible with caffeine that directly opens sarcoplasmic reticulum $\mathrm{Ca}^{2+}$ channels, thereby bypassing the ECC pathway (Warren et al. 1993). Later, sarcoplasmic reticulum membrane is affected as well because it is linked to the T-tubule system by junctophilins. Mouse studies indicate that these play a pivotal role in the interaction between the dihydropyridine receptors on the T-tubule membrane and the ryanodine $\mathrm{Ca}^{2+}$ release channels on the sarcoplasmic reticulum (Fig. 1) (Corona et al. 2010). Plasma and sarcoplasmic reticulum membrane damage result in uncontrolled $\mathrm{Ca}^{2+}$ entry into the sarcoplasm, triggering a local injury contracture and raising muscle passive tension, in addition to a fall in active tension (Allen et al. 2005). Interestingly, the ability of artificially increased intracellular $\mathrm{Ca}^{2+}$ concentration to cause muscle damage was first demonstrated experimentally by Duncan already in 1978 (Duncan 1978). In the early 90s, Duan and coworkers then showed that $\left[\mathrm{Ca}^{2+}\right]_{\mathrm{i}}$ actually rises in skeletal muscle of laboratory rats after prolonged downhill walking (Duan et al. 1990). Elevated $\left[\mathrm{Ca}^{2+}\right]_{\mathrm{i}}$ subsequently activates the phospholipase-prostaglandin pathway and the calpain proteolytic pathway (Clarkson and Sayers 1999, Huang and Zhu 2016). The activated phospholipase A2 promotes further muscle cell damage 


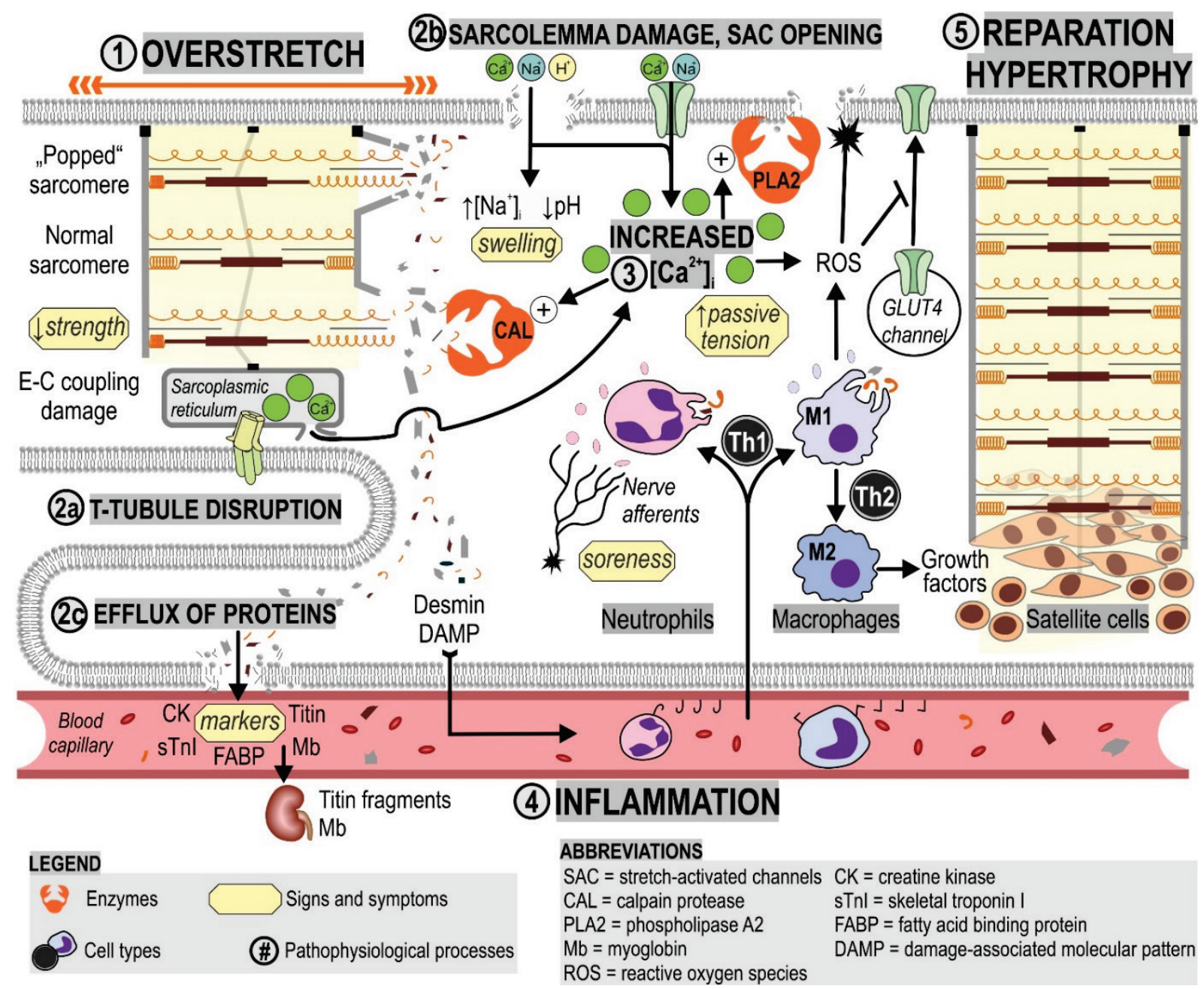

Fig. 1. Proposed crucial molecular mechanisms of exercise-induced muscle damage etiopathogenesis, symptoms, and the reparation process. 1) Increased tension in eccentric exercise overstretches some of the weakest sarcomeres beyond their myofilament overlap. Such "popped sarcomeres" are unable to produce active tension, which results in direct loss of strength. Increasing external tension causes stronger sarcomeres to pop and gradually overburdens other structures. 2a) First, T-tubule membrane system disruption occurs. ECC dysfunction contributes to even greater strength loss and SR membrane damage results in an uncontrolled $\mathrm{Ca}^{2+}$ release, which raises passive muscle tension. 2b) Opening of stretch-activated channels (SAC) and sarcolemma damage lead to increased $\left[\mathrm{Na}^{+}\right]_{\mathrm{i}}$ and $\left[\mathrm{Ca}^{2+}\right]_{\mathrm{i}}$, swelling and drop in $\mathrm{pH}_{\mathrm{i}} .2 \mathrm{c}$ ) Efflux of intracellular muscle proteins, which can be used as EIMD markers in plasma (FABP, CK, sTnI, titin, Mb) or in urine (titin fragments, Mb) (Kanda et al. 2017). 3) Increased [Ca $\left.{ }^{2+}\right]_{i}$ contributes to cellular injury via activation of calpain protease (CAL), which cleaves Z-disc associated proteins and activation of PLA2, which promotes further sarcolemma damage. High $\left[\mathrm{Ca}^{2+}\right]_{i}$ also raises $\mathrm{Ca}^{2+}$ concentration in mitochondria, which promotes ROS production. 4) Muscle breakdown products such as DAMP and desmin trigger inflammatory response, which causes further swelling. The first part of inflammation is orchestrated via Th1 cytokines. Neutrophils are first to invade and are followed by M1 macrophages. The role of both is to clear necrotic debris through phagocytosis. Cytotoxic enzymes and ROS cause further cellular injury. The latter are probably also responsible for decreased GLUT4 translocation to sarcolemma (for more detail, see Fig. 2). Substances like BK, PG and 5-HT are exciting and/or sensitizing type III and IV nerve afferents producing feeling of soreness. Gradually, Th2 cytokines start to predominate which causes a shift from pro-inflammatory M1 to pro-regenerative M2 macrophage phenotype population that releases anti-inflammatory cytokines (e.g. IL-10) and growth factors. 5) The latter activate satellite cells, which serve as so-called stem cells of skeletal muscle precursor cells. Activated satellite cells migrate to areas where they differentiate and fuse with existing myofibers or produce new fibers which increases the transcriptional capacity of muscle. This results in muscle reparation by adding new sarcomeres in series. Thus, the described mechanism of muscle damage also plays a role in muscle hypertrophy (Damas et al. 2018, Paulsen et al. 2012).

*) Not shown in the figure above is the damage of the extracellular matrix, which is mechanically linked to muscle fiber cytoskeleton via membrane-spanning integrin, dystroglycan, and proteoglycan complexes, and also plays an important role in the pathogenesis of EIMD (Hyldahl and Hubal 2014).

via cell membrane breakdown, resulting in leakage and loss of intracellular components (McKune et al. 2012). Calpain 3, a relatively muscle-specific $\mathrm{Ca}^{2+}$-activated protease located at the $\mathrm{Z}$ regions of skeletal muscle putatively plays a crucial role in the enzymatic degradation (Branca et al. 1999, Goll et al. 2003). Calpain cleaves Z-disc associated cytoskeletal proteins, e.g., desmin, vimentin, and $\alpha$-actinin, whereas actin and myosin are not recognized by calpain as substrates and are therefore largely spared. This is believed to explain 
why damage can be found predominantly at the Z-disc regions (Clarkson and Sayers 1999, Huang and Zhu 2016, McKune et al. 2012). We discuss the possible routes of $\mathrm{Ca}^{2+}$ entry into the sarcoplasm and the possible pathways through which it reduces force production, increases protein breakdown and plasma membrane permeability into more detail in Chapter 3.

\subsection{Extracellular matrix and membrane channels}

The third factor contributing to the mechanical muscle damage is the disruption of muscle connective tissue (i.e., extracellular matrix, ECM), which is a network of primarily collagens linked to membranespanning integrin, dystroglycan, and proteoglycan complexes (Fatouros and Jamurtas 2016, Gibala et al. 1995, Stauber et al. 1990). These complexes link the ECM to the cytoskeleton thereby enabling the transmission of force from the exterior into the interior of the muscle cells and vice versa (Heinemeier et al. 2013, Kjaer 2004). On the other hand, mechanical disturbance of ECM following eccentric muscle damage may play a role in activating intracellular cascades of biochemical reactions not only in muscle cells themselves but also in various other types of cells within the muscle tissue, e.g., vascular, inflammatory, stromal, and satellite cells. This may lead to transcription and excretion of different growth factors and other molecules involved in regeneration and adaptation (Fatouros and Jamurtas 2016, Hyldahl and Hubal 2014). Finally, vigorously stretching myofibrils, which results in membrane damage, also affects the channels located on the sarcolemma, particularly the stretch-activated channels. Following eccentric exercise, a persistent increase in intracellular $\mathrm{Na}^{+}$and $\mathrm{Ca}^{2+}$ has been demonstrated (Allen 2004, Allen et al. 2010), as well as an increase in membrane permeability for different muscular proteins that can subsequently be measured in plasma and used as biomarkers for EIMD, with creatine kinase and myoglobin being the most prominent ones (Sorichter et al. 1999). More details regarding changes in membrane permeability and ionic composition are provided later.

\subsection{Inflammation}

It was shown in both humans and laboratory animals that a strong inflammatory response follows eccentric exercise and importantly contributes to EIMD (Chazaud 2016, Fatouros and Jamurtas 2016, Hayashi et al. 1997). The inflammatory response can be detected immediately after exercise with leukocytosis, accounted for mainly by a transient increase in neutrophil counts which is most strongly pronounced within the first 24 hours (Close et al. 2004). A transfer of fluid and plasma proteins into the damaged muscle tissue follows this neutrophil increase, as well as mobilization of other inflammatory cells, e.g., natural killer cells and lymphocytes. More specifically, neutrophils of the Ly6C/F4/80 type are the first to invade the muscle tissue as early as within 2 hours after an exercise bout, possibly being attracted by cleavage products of calpain-mediated protein breakdown (Tidball and Villalta 2010). They partly contribute to muscle injury but also start clearing necrotic debris through phagocytosis, working in conjunction with resident macrophages. Neutrophils can remain present in supra-physiological numbers for as long as 5 days (Belcastro et al. 1998, MacIntyre et al. 1995, McKune et al. 2012, Peake et al. 2005a, Tidball 2005). However, tissue macrophages replace them in most cases within the first day, becoming the predominant leukocyte cell type in the injured muscle and remaining there for up to 2 weeks (Peake et al. 2005a, 2017a). Local production of pro-inflammatory cytokines (e.g., interleukin(IL)-1 $\beta$ and tumor necrosis factor (TNF)- $\alpha$ ) by muscle cells themselves begins and persists for up to 5-days post exercise (Peake et al. 2005a, 2015). This drives the differentiation of early macrophages to an M1 phenotype (also called CD68+, macrosialin or $\mathrm{ED} 1+$ ), which peaks in concentration at about 2 days post-exercise (Tidball and Villalta 2010). Similarly to neutrophils, M1 macrophages are capable of producing proteolytic enzymes as well as reactive oxygen and nitrogen species (ROS and RNS, respectively) during a process called the respiratory burst (Tidball 2005, Tidball and Villalta 2010). Similarly to neutrophils, they partly aggravate the existing mechanical damage but are predominantly involved in the removal of cellular debris (Powers et al. 2011). Importantly, the increase in reactive oxygen species (ROS) probably contributes to a decrease in insulin-induced glucose uptake in muscle cells due to decreased GLUT4 translocation to sarcolemma (Aoi et al. 2012). We will discuss this aspect in more detail later.

The inflammatory processes mediated by neutrophils play a role in degradation of damaged muscle tissue by producing reactive oxygen species (ROS) and attracting macrophages (McGinley et al. 2009). Reactive oxygen species are generally toxic to cells but as shown in mice, may function as a secondary messenger in the regulation of gene expression resulting in ROS-mediated adaptation to exercise (Crane et al. 2013, Schoenfeld 
2012). In addition to ROS, cytokines with pro- or antiinflammatory roles are expressed by inflammatory and muscle cells. One of the most important cytokines is TNF- $\alpha$ that can activate the ubiquitin-proteasome pathway for protein degradation by increasing gene expression of E3 ligases, muscle ring finger 1 (MuRF1) and muscle atrophy F-box (MAFbx or Atrogin1), thereby taking part in muscle remodeling after damaging exercise (Murton et al. 2008, Patel et al. 2014).

After approximately 2 days, M1 macrophages are gradually replaced by different subsets of M2 (ED2+) macrophages under the influence of Th2 cytokines (e.g., IL-4, IL-10, and IL-13). This switch is believed to play a pivotal role in repair and remodeling via activation of satellite cells (McKune et al. 2012, Tidball and Villalta 2010). Apart from immune cells, vascular pericytes take part in EIMD by activating signaling cascades via the nuclear factor-kappa B (NF- $\mathrm{B})$, thus stimulating proliferation of satellite cells and mobilization of immune cells (Hyldahl et al. 2011, 2013, Michailidis et al. 2013, Wright et al. 2015). In both humans and rats there is also evidence that the inflammatory response is accompanied by increased muscle blood flow and microvascular dysfunction (Kano et al. 2005, Laaksonen et al. 2006).

Moreover, muscle cells themselves play an active role in attenuating the inflammatory processes. During exercise muscle cells produce anti-inflammatory myokines, among which IL-6 was identified first and is the the most studied (Hennigar et al. 2017, Pedersen et al. 2007, Pedersen and Febbraio 2008). Plasma IL-6 concentration increasses exponentially during strenuous exercise. When macrophages produce IL-6, it results in inflammatory processes, whereas when muscle cells release it, the classical pro-inflammatory pathway is not activated and its effects are rather anti-inflammatory (Hennigar et al. 2017, Pedersen 2011a, 2011b, Pedersen et al. 2007, Pedersen and Febbraio 2008). During exercise, the circulating levels of other anti-inflammatory cytokines, such as IL-1 receptor antagonist, IL-4, and IL-10, also increase, mediating a systemic antiinflammatory response to EIMD (Malm 2001, Malm et al. 2000, Peake et al. 2005a). Although some myokines can promote leukocyte infiltration, muscle-derived NO strongly inhibits leukocyte invasion and protects the muscle from further lysis by inflammatory cells (Tidball 2005). Following exercise which lasts for up to $1 \mathrm{~h}$, exercise intensity appears to be the most important determinant of the extent of anti-inflammatory cytokine production (Peake et al. 2005b). Finally, it should be pointed out that inflammation seems to play a crucial role in EIMD especially after eccentric contraction, whereas in cases of EIMD associated with prolonged and intensive endurance training, inflammation may be much less pronounced (Tee et al. 2007, Warhol et al. 1985).

\subsection{Metabolic factors}

Although the mechanical stress model with myofibrillar overstretch as the initial event in the pathogenesis of EIMD is the most popular and accepted, evidence exists that metabolic factors may play an initial role in cases of EIMD following endurance exercises where eccentric contraction is less important. The metabolic stress hypothesis predicts that focal depletion of glycogen stores leads to a lack of ATP and a decreased function of the sarcoplasmic reticulum or sarcolemmal ATPases. This is believed to cause an elevation in cytoplasmic $\mathrm{Ca}^{2+}$ and activation of calcium-dependent proteolytic and phospholipolytic pathways, resulting in degradation of cytosolic proteins and membranes, converging with the mechanical stress pathway (Armstrong 1986, Armstrong et al. 1991, Tee et al. 2007). Moreover, temperature and metabolically produced ROS may play a role as initiating factors (Morton et al. 2009). Finally, at the structural level, metabolic stress was shown to be accompanied by focal mitochondrial damage in the form of matrix loss and dissolution of cristae (Warhol et al. 1985).

\subsection{Genetic variability}

Many genes for key muscle proteins and cytokines show polymorphisms that alter gene expression and subsequent protein production. This influences both the extent of injury and the ability to recover from EIMD (Baumert et al. 2016, Clarkson et al. 2005). For instance, individuals with specific single nucleotide polymorphisms (SNPs) in the gene for collagen I (COL1A1, rs1800012, rs2249492) are generally weaker, experience greater muscle soreness and slower postEIMD recovery compared to homozygote counterparts, possibly because of a disrupted collagen network (Baumert et al. 2018b). Furthermore, subjects homozygous for rare alleles of the myosin light chain kinase (MLCK 49T or MLCK 3788A), experience a greater increase in plasma creatine kinase $(\mathrm{CK})$ and myoglobin $(\mathrm{Mb})$ following eccentric exercise, posing a risk of kidney failure due to exertional rhabdomyolysis (Clarkson et al. 2005). A SNP in the ACTN3 gene coding for $\alpha$-actinin-3, which anchors actin filaments to Z-lines 
(Mills 2001), is associated with smaller muscle volumes as well as lower muscle strength and power in individuals with $\alpha$-actinin-3 deficiency (ACTN3 R577X, rs1800795, XX genotype) (Baumert et al. 2016, Erskine et al. 2014). On the other hand, their Z-lines are more elastic and consequently less prone to stretch-shortening cycle movements, and they also have lower baseline $\mathrm{CK}$ compared to heterozygotes (Broos et al. 2012, Clarkson et al. 2005, Venckunas et al. 2012). There are also genetic variations in the gene for MuRF-1 (TRIM63 gene), which may affect mechanical properties of titin. The TRIM63 AA homozygous individuals (A>G, rs2275950) are consistently stronger, report less muscle soreness and have greater titin stiffness compared to the GG homozygotes, leading to intrinsically stronger as well as more EIMD-resistant muscle fibers (Baumert et al. 2018a).

Benefits to athletic performance have been suggested for individuals carrying the IL1RN allele-2 for interleukin-1 who display only a moderate IL-1dependent inflammation supporting a faster recovery or remodeling (Cauci et al. 2010). Furthermore, genetic modification or blocking of the angiotensin-II receptor type 1, which is involved in post-exercise inflammation, was shown to improve regeneration (Bedair et al. 2008) and decrease ROS production (Sim et al. 2013). On the other hand, angiotensin-II indirectly mediates skeletal muscle damage by influencing angiogenesis (Vaughan et al. 2013) and glucose metabolism in response to exercise (Vaughan et al. 2016). Polymorphisms of genes coding for other cytokine factors, such as interleukin-6, osteopontin, chemokine-ligand-2 and chemokinereceptor-type-2, have also been identified but require further investigation to fully elucidate their role in the extent of inflammatory muscle damage (Baumert et al. 2016, Hubal et al. 2010).

Following EIMD, regeneration and remodeling are governed by growth factors. Among these are the insulin-like growth factor-I (IGF-I) and IGF-II, IGF-binding proteins, the insulin receptor, and cell surface receptors, such as IGF-I receptor and IGF-II receptor (Duan et al. 2010, Jiao et al. 2013, Mackey et al. 2011). The same factors are involved in exercise-induced muscle hypertrophy (Matheny et al. 2009, Sharples and Stewart 2011). Different isoforms of IGF-I stimulate satellite cells in muscle to proliferate and differentiate, and IGF-I overexpression was shown to significantly increase muscle cross-sectional area after a chronic muscle overload (Paul and Rosenthal 2002). Specifically, insulin-like growth factor-IEb expression increases in response to muscle damage stimulating myoblast fusion (Jiao et al. 2013, Yang and Goldspink 2002). Moreover, IGF-IEc protects muscle cells from ROS during the inflammatory phase after EIMD by enhancing the activity of superoxide dismutase (Dobrowolny et al. 2005). Furthermore, as IGF-I regulates collagen synthesis, decreased IGF-I levels induced by IGF SNPs may negatively influence the stability of the extracellular matrix and cause decrease in strength (Hansen et al. 2013). Similarly, several different SNPs of IGF-II have been associated with EIMD, which might to some extent be explained by IGF-II playing a role in extracellular matrix integrity (Baumert et al. 2016).

As strenuous exercise results in oxidative stress and ROS production, any reduction of the anti-oxidative capacity of cells is expected to increase EIMD. A single nucleotide polymorphism Ala16Val (rs4880, C $>$ T) in the superoxide dismutase 2 (SOD2) gene results in reduced efficiency of SOD2 and consequently increases EIMD susceptibility (Shimoda-Matsubayashi et al. 1996) and creatine kinase concentration after exercise (Akimoto et al. 2010).

Additionally, a gene polymorphism involving the allele-D for angiotensin-I converting enzyme (ACE) has been associated with increased muscular strength in humans (Williams et al. 2005), lower creatine kinase in plasma following strenuous exercise (Yamin et al. 2007), and decreased pain sensitivity due to shorter bradykinin half-life (Baumert et al. 2016).

Since we will later discuss the effects of EIMD on insulin sensitivity, we wish to conclude this section with an example of how variability in insulin secretion might affect susceptibility to EIMD. In type 2 diabetes mellitus, insulin resistance is often accompanied by down-regulation of the zinc transporter solute carrier family 30 member 8 , which is a product of the SLC30A8 gene (Somboonwong et al. 2015). As the disturbed zinc homeostasis affects insulin crystallization and secretion (Chen 2015, Lemaire et al. 2009), carriers of the C-allele of SLC30A8 (C>T) SNP (rs13266634) have more than a $50 \%$ greater risk of developing type 2 diabetes than T-allele carriers. Protein synthesis decreases in their muscle cells due to the lower insulin level, probably resulting in longer recovery time after strenuous exercise. In contrary, individuals with the TT genotype of the SLC30A8 SNP show smaller strength loss and soreness as well as lower plasma $\mathrm{CK}$ and myoglobin concentration after eccentric exercise (Sprouse et al. 2014). For more 
genetic aspects on EIMD, see the excellent review by Yamin and coworkers (Yamin et al. 2014).

\section{Consequences of EIMD}

\subsection{Structural and mechanical consequences of EIMD}

Following eccentric exercise, structural changes at the cellular level include unaligned, overextended sarcomeres, or even occurrence of so called halfsarcomeres, regional disorganization of myofilaments, Z-line streaming, disrupted I-bands, disorganized cytoskeletal elements, such as desmin, dystrophin and other proteins, T-tubule damage, autophagic vacuoles, displaced organelles, swollen mitochondria, and intramuscular capillary damage (McKune et al. 2012, Morgan and Allen 1999). The disruption of muscle's structure affects its mechanical properties, which can be quantified as a right shift in the muscle's active lengthtension diagram due to an increase in series compliance (Katz 1939, Morgan 1990). Furthermore, a prominent active tension decline develops, which is closely associated with the disruption of T-tubules and sarcoplasmic reticulum membranes as well as with an impaired ECC. It is worth pointing out that the decline in active tension is not due to disruption of sarcomeres in series per se. In a series of sarcomeres, the recorded force does not depend on the number of sarcomeres in series. In other words, if some sarcomeres fail to produce force, this does not necessarily affect the produced force. It only shifts the length-force curve to longer lengths, i.e., to the right (Morgan and Allen 1999, Proske and Morgan 2001). However, since eccentric exercise also brings about membrane damage and disrupted ECC, the force production is affected as well (Allen 2001, Proske and Morgan 2001). It should also be noted that in addition to the abovementioned membrane and ECC changes, the active tension decline following eccentric exercise also includes a metabolic component common to all exercise types. Therefore, a comparable concentric exercise should be used as a control when assessing the tension decline after eccentric exercise (Allen 2001, Morgan and Allen 1999).

Immediately after eccentric exercise, muscle stiffness increases due to a rise in passive tension and remains elevated for a few successive days. This stiffness possibly results from various factors, including stretchactivated $\mathrm{Ca}^{2+}$ entry, local contracture of fiber segments caused by the T-tubule and SR membrane damageassociated rise in $\mathrm{Ca}^{2+}$, or from shortening of parallel non-contractile elements within the muscle tissue (Howell et al. 1993, Jones et al. 1987, Proske and Morgan 2001). The described increase in passive tension after a series of eccentric contractions is largest at sarcomere lengths close to the optimum for active tension (Whitehead et al. 2001). Type II muscle fibers are more susceptible to EIMD (Macaluso et al. 2012) and this has been ascribed to lower levels of cytoskeletal proteins mechanically supporting sarcomeres and heat shock proteins that normally protect the muscle from mechanical stress and enhance recovery (Folkesson et al. 2013, Koh 2002, Liu et al. 2006, McKune et al. 2012). In addition, a lower oxidative capacity, a higher capacity to generate tension, and a shorter optimum length for tension generation may all contribute to greater vulnerability of type II fibers (Douglas et al. 2017a, Proske and Morgan 2001, Qaisar et al. 2016).

\subsection{Electrophysiological, ionic, and molecular consequences of EIMD}

Membrane tears and increased open probability of stretch-activated channels and possibly other channel types, such as store-operated channels, leak, and growth factor-regulated channels, are believed to be responsible for characteristic ionic and electrophysiological disturbances observed in damaged muscle fibers (Allen et al. 2005, Gailly 2012). Following eccentric contractions, resting $\left[\mathrm{Ca}^{2+}\right]_{\mathrm{i}}$ increases within minutes and stays elevated for hours and this rise is accompanied by a fall in tetanic $\left[\mathrm{Ca}^{2+}\right]_{\mathrm{i}}$ (Balnave and Allen 1995, 1996, Lynch et al. 1997). As mentioned in the previous chapter, this reduced $\mathrm{Ca}^{2+}$ release from SR probably explains the part of performance reduction that cannot be attributed to mechanical displacement of myofibrils (Warren et al. 1993). The increase in resting $\left[\mathrm{Ca}^{2+}\right]_{i}$ is probably mostly due to influx from the extracellular space via stretchactivated channels rather than from internal stores, since it can be prevented by omission of extracellular $\mathrm{Ca}^{2+}$ and by specific blokers of this type of channels and the release from SR can be rescued by caffeine (Allen et al. 2005). The described changes in $\left[\mathrm{Ca}^{2+}\right]_{\mathrm{i}}$ are especially pronounced in the mdx mouse model of human Duchenne muscular dystrophy. This confirms the role of stretch in eliciting the pathophysiological cascade and highlights the importance to understand its elements for not only prevention and treatment of EIMD, but also to find new molecular targets to treat muscular dystrophies (Allen et al. 2010, Yeung et al. 2005). $\mathrm{Na}^{+}$ions also have a large inward electrochemical gradient and since stretch- 
activated channels are permeable also to $\mathrm{Na}^{+}$, intracellular $\mathrm{Na}^{+}$concentration $\left(\left[\mathrm{Na}^{+}\right]_{\mathrm{i}}\right)$ rises alongside $\left[\mathrm{Ca}^{2+}\right]_{\mathrm{i}}$ following eccentric contractions (Yeung et al. 2003). The increase in $\left[\mathrm{Na}^{+}\right]_{\mathrm{i}}$ probably accounts for osmotic inflow of water, swelling, and vacuolization, as well as at least partly for a decrease in $\mathrm{pH}$ due to a reduced efficiency of the $\mathrm{Na}^{+} / \mathrm{H}^{+}$exchanger (Foley et al. 1999, Yeung et al. 2002a, Yeung et al. 2002b). Another mechanism for the decrease in $\mathrm{pH}$ may be an increased inward leak of $\mathrm{H}^{+}$ (Allen et al. 2005). Most importantly, due to the increase in $\left[\mathrm{Na}^{+}\right]_{i}$, the Nernst diffusion potential for $\mathrm{Na}^{+}$becomes less and together with the increased permeability for $\mathrm{Na}^{+}$, the membrane depolarizes. Using glass microelectrode measurements in rat muscle studies, McBride and coworkers demonstrated that following eccentric contractions, membrane potential depolarizes by approximately $10 \mathrm{mV}$ for at least $24 \mathrm{~h}$. Similarly to the rise in $\left[\mathrm{Ca}^{2+}\right]_{\mathrm{i}}$, depolarization could partly be prevented by stretch-activated channel blockers, indicating the central role of these channels in both processes (McBride et al. 2000). However, stretch-activated channels are expected to deactivate within seconds after mechanical activation. Since the dynamics of depolarization is rather slow, there is probably another mechanism which governs the behavior of these channels, such as damage of cytoskeletal proteins conveying the mechanical force (Guharay and Sachs 1984). Some part of depolarization, especially in older animals, is probably due to membrane tears (McBride 2000). Conceivably, membrane depolarization can inactivate voltage-sensitive $\mathrm{Na}^{+}$channels, reduce action potential amplitude, and thus attenuate $\mathrm{Ca}^{2+}$ release (Allen et al. 2005). Furthermore, decreased $\mathrm{pH}$ can reduce myofibrillar $\mathrm{Ca}^{2+}$ sensitivity and also the increased $\left[\mathrm{Ca}^{2+}\right]_{\mathrm{i}}$ itself could contribute to reduced $\mathrm{Ca}^{2+}$ release via a calpain 3-dependent process (Fabiato and Fabiato 1978, Verburg et al. 2005, Westerblad et al. 2000). In addition to reduced force production, increased $\left[\mathrm{Ca}^{2+}\right]_{\mathrm{i}}$ can also account for calpain-mediated protein breakdown and phospholipaseand ROS-dependent damage and increased membrane permeability (Belcastro et al. 1998, Huang and Zhu 2016). Finally, it should be noted that beside the crucial role of the abovementioned changes in fatigue, there is strong evidence that the same stretch-activated channeldependent increase in $\left[\mathrm{Ca}^{2+}\right]_{\mathrm{i}}$ is crucial for hypertrophy via mechanisms that have been excellently reviewed elsewhere (Spangenburg and McBride 2006, Zanchi and Lancha 2008).

The above changes at the (sub)cellular level are accompanied by characteristic changes in extracellular recordings. Behrens and coworkers measured the changes in excitability of alpha motor neurons after EIMD at the spinal level. By using the H-reflex technique, they showed that maximal H-reflex (H-max), maximal M-wave (M-max), and the ratio of H-max to M-max were not affected by EIMD, while the isometric maximal voluntary contraction was impaired. Their data suggest no association between muscle soreness and voluntary muscle activation or spinal nerve excitability (Behrens et al. 2012). When measuring discharge rate of human motor neurons, Hedayatpour and coworkers found no significant impairment by EIMD (Hedayatpour et al. 2009). However, the same was not true for the conduction velocity of muscle motor units. Surface and fine-wire intramuscular EMG measurements on two locations of vastus medialis showed a decrease in motor unit conduction velocity up to $10 \%$ over 24 - to 48 -hours following EIMD (Hedayatpour et al. 2009). Moreover, during sustained contractions, at 24 and $48 \mathrm{~h}$ postexercise, the motor unit conduction velocity decreased over time at faster rates compared to control without previous eccentric exercise, confirming that the electrophysiological membrane properties of muscle fibers are altered by EIMD (Hedayatpour et al. 2009). Human studies of Semmler and coworkers show significant changes in many EMG-related muscle parameters, among which are up to 2-times increased EMG amplitudes and force fluctuations during submaximal contractions of muscles following eccentric exercise (Dartnall et al. 2008, Dundon et al. 2008, Semmler 2014, Semmler et al. 2007). Examining these changes in detail, the authors suggested that the reasons for increased submaximal EMG after eccentric exercise could include a decrease in motor unit conduction velocity and an increased antagonist muscle co-activation to maintain the required submaximal force (Semmler 2014). Compared to concentric exercise, eccentric exercise causes a greater and longer-lasting reduction in conduction velocity (Piitulainen et al. 2011). Further data revealed a decrease in mean motor unit recruitment threshold (biceps brachii, $41 \%$ and $39 \%$ reduction immediately after and $24 \mathrm{~h}$ after exercise, respectively) and an $11 \%$ faster minimum tonic discharge rate and variability (Dartnall 2009). Importantly, motor unit synchronization and coherence at low frequencies increased up to $>30 \%$ immediately and $24 \mathrm{~h}$ after eccentric exercise and up to $57 \% 1$ week later later (Dartnall et al. 2008, 2011). In sum, these studies 
indicate that EIMD alters the behavior of motor units, including their conduction velocities and synchronization which points to an impaired motor control and altered motor unit activation for up to 1 week (Semmler 2014). The changes in motor unit activity seem to be compensated by the central nervous system with an increase in neural drive during submaximal isometric contractions (Piitulainen et al. 2011).

\subsection{Metabolic consequences of EIMD}

Non-damaging muscle contraction stimulates glucose uptake in an intensity- and duration-dependent manner via the GLUT4 transporter, both synergistically and independently of insulin, in the latter case even more potently than insulin alone (Ahlborg et al. 1974, Wallberg-Henriksson et al. 1988, Youn et al. 1991). Thus, from a clinician's and patient's point of view muscle activity is an attractive and possibly highly efficient measure for achieving and maintaining euglycemia in both type 1 and type 2 diabetes (T2D) and the metabolic syndrome (Buresh and Berg 2018, Codella et al. 2017, Egan and Zierath 2013, Evans et al. 2019). This is highlighted by the fact that the skeletal muscle is quantitatively the most important glucose sink and accounts for about $80 \%$ of glucose disposal under insulin-stimulated conditions, and that insulin resistance in skeletal muscle is the primary defect in pathogenesis of T2D (DeFronzo et al. 1981, Goodyear, PhD and Kahn, MD 1998, Ryder et al. 2001, Tumova et al. 2016). Importantly, non-damaging exercise also corrects the defective insulin signaling cascade (Zierath 2002). Despite the practical importance of exercise and the potential that understanding the intracellular signals mediating contraction-stimulated glucose uptake may suggest novel drug targets, the molecular mechanisms elicited by contraction are much less studied and understood compared to the ones elicited by insulin (DeFronzo et al. 2015, Richter and Hargreaves 2013, Stanford and Goodyear 2014). Even less is known about specific effects of damaging eccentric contractions and EIMD (Andersen et al. 2019, Aoi et al. 2013, Asp et al. 1997, Jentjens and Jeukendrup 2003). Therefore, we first briefly review the main metabolic effects of exercise in general and then of EIMD in specific.

A part of the increased glucose uptake during exercise might be due to enhanced insulin signaling through the classical phosphytidylinositol 3-kinase (PI3K)/Akt/TBC1D4 signaling cascade (Hayashi et al. 1997, Higaki et al. 2008, Richter and Hargreaves 2013).
However, the major part of contraction-dependent increase in glucose uptake is probably insulinindependent. The classical view is that $\mathrm{Ca}^{2+}$ released from the endoplasmic reticulum and its downstream $\mathrm{Ca}^{2+}$-dependent proteins, such as PKC isoforms, $\mathrm{Ca}^{2+} /$ calmodulin-dependent kinase CaMKII, NSPL1, and CaMKK, are mainly responsible for the contractiondependent glucose uptake (Jensen et al. 2014, Youn et al. 1991). However, some recent reports have suggested that $\mathrm{Ca}^{2+}$ is neither sufficient nor necessary for maximum contraction-dependent glucose transport response and that the metabolic and mechanical stress associated with contraction play a much more important role than $\mathrm{Ca}^{2+}$.

In other words, there is probably an insulinindependent, AMPK-dependent signaling pathway and an insulin-independent, mechanical stress-dependent pathway. On the one hand, a rapid turnover of ATP is believed to activate AMPK and its downstream targets, among which TBC1D1, NO synthases, PIKfyve, NSPL1, and/or the RalA GAP protein GARNL1 are the proposed candidates, and translocate GLUT4 to the plasma membrane. On the other hand, the mechanical stress itself brought about by contraction can activate glucose transport via much less well-understood secondary messengers and signaling cascades. Among the proposed signaling molecules and mechanisms are the AMPKrelated kinase SNARK, ROS, and the actin cytoskeletonregulating GTPase Rac1 (Jensen et al. 2014, Pirkmajer and Chibalin 2016, Stanford and Goodyear 2014, Sylow et al. 2014b, 2015, 2016). Rac1, which is essential for transmitting mechanical stress to increased glucose uptake, is probably also involved in the insulin-dependent pathway, demonstrating that the described intracellular pathways originating from different signals can at least partly converge (Sylow et al. 2014a, 2014b). Overall, muscle activity can acutely increase insulin sensitivity. This effect is immediate and usually persists for several hours or days, which is why physical activity is especially important for type 2 diabetic patients. Long-term effects of regular bouts of exercise lead to an additively improved whole-body glucose tolerance, but the majority of the observed improvement can still be explained by the last bout of exercise (Tee et al. 2007). A concise graphical summary of the described events is given in Figure 2.

In stark contrast with the above effects, a bout of eccentric exercise resulting in EIMD causes a decreased insulin sensitivity due to disturbed intracellular insulin signaling and less GLUT4 in the plasma membrane 


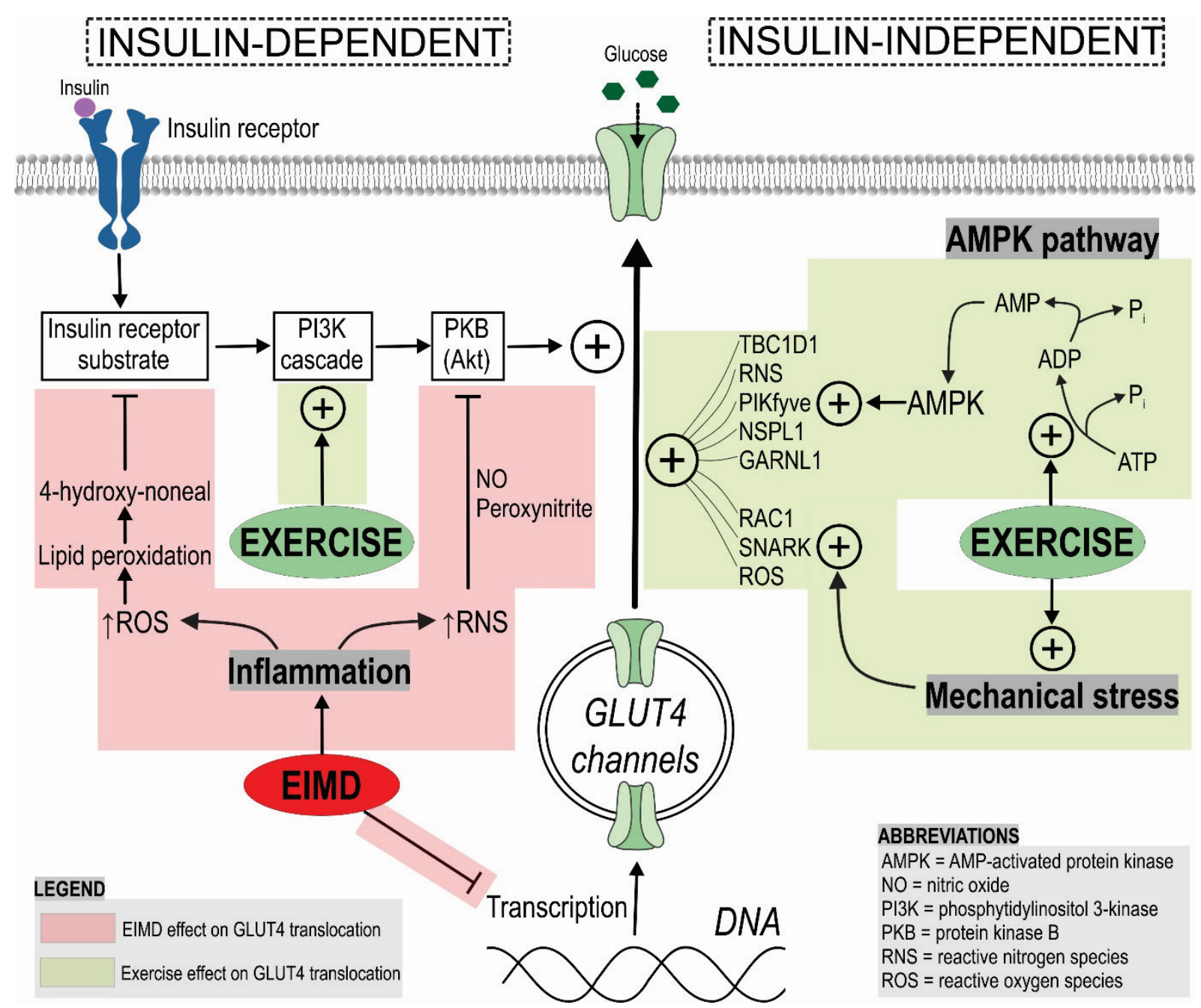

Fig. 2. Exercise and EIMD effect on GLUT4 channel translocation to sarcolemma. Moderate exercise promotes, whereas EIMD impedes GLUT4 channel translocation to sarcolemma and thus glucose entry into a muscle cell. See how proposed mechanisms of moderate exercise affect both insulin-independent and insulin-dependent GLUT4 channel translocation. EIMD on the other hand is believed to affect mostly the latter pathway leading to decreased insulin sensitivity. Interestingly, some molecules such as ROS, RNS and RAC1 appear in both pathways. The exact molecular and clinical effects of those and many other molecules involved in GLUT4 channel translocation remain to be elucidated.

(shown on the left side of Fig. 2). Additionally, EIMD is associated with glycogen depletion due to higher glycogen use or slower repletion due to the observed decrease in insulin sensitivity. Furthermore, glucose metabolism displays a decrease in oxidative and an increase in non-oxidative glucose degradation, accompanied by an increased lactate response to exercise and an increased metabolic rate. This is probably a consequence of damage to the oxidative machinery and a preferential recruitment of type II fibers in the period following EIMD, whereas the increased metabolic rate is a consequence of repair processes or a decreased efficiency of the oxidative metabolism. Interestingly, these shifts in the metabolic profile of glucose are more strongly pronounced in cases where metabolic stress predominates over mechanical stress (Evans et al. 2019,
Gavin et al. 2018, Hughes et al. 2013, Tee et al. 2007). In contrast, the decreased content of GLUT4 is more strongly associated with EIMD after mechanical than after metabolic stress (Asp et al. 1997).

The oxidative stress after eccentric exercise mediated by inflammatory cells could be one of the main culprits for the impaired insulin-stimulated glucose uptake as well as post-exercise glucose utilization (Aoi et al. 2012). The increase in ROS, especially hydrogen peroxide $\left(\mathrm{H}_{2} \mathrm{O}_{2}\right)$, leads to lipid peroxidation, its major product being 4-hydroxy-noneal. It accumulates in cells and subsequently modifies insulin signal transduction by non-enzymatically and irreversibly changing the amino acid sequence of target proteins, including the insulin receptor substrate 1 (IRS-1) (Aoi et al. 2012, Wei et al. 2008). Simultaneously, the content of GLUT4 
transporters and their translocation to sarcolemma drop significantly (Aoi et al. 2012, Asp et al. 1997). The same goes for the GLUT4-mRNA concentration, pointing to a decreased transcription rate (Kristiansen et al. 1997). Concentrations of many enzymes and different factors have been reported to change following eccentric exercise and might be associated with the decreased GLUT4 content (Richter and Hargreaves 2013). More specifically, it has been shown that phosphorylation of insulin receptor beta and protein kinase B (Akt) decrease, while phosphorylation of the I-kappaB kinase alpha and beta (pIKKalpha/beta), the stress-activated protein kinases/Jun amino-terminal kinases (pSAPK-JNK), the nuclear factor kappa B (NF-kappaB), and the insulin receptor substrate IRS-1 increase after a downhill running protocol (Morais et al. 2018, Pereira et al. 2016a).

Another putative source of oxidative damage and thus insulin resistance during EIMD are reactive nitrogen species (RNS). It has been shown that the production of nitric oxide (NO) and the activity of nitric oxide synthase (NOS) increase during muscle contraction/exercise (Balon and Nadler 1997, Roberts et al. 1999). This is believed to subsequently increase contraction-stimulated glucose uptake (Higaki et al. 2001, Merry et al. 2010). However, simultaneous presence of high levels of ROS on respiratory chain complexes I and III in fast twitch muscle fibers, as well as NOS stimulation and the subsequent increase in contraction-stimulated glucose uptake, lead to an increased production of RNS in fast-twitch muscle fibers and render them more prone to oxidative damage (Anderson and Neufer 2006, Merry et al. 2010). One important RNS is peroxynitrite, which causes lipid peroxidation, DNA damage, and nitrosylation of proteins including Syntaxin 4, a key molecule in insulin exocytosis, and nitration of Akt, a key factor in insulin signaling (Duplain et al. 2008, Hsu et al. 2016, Korbecki et al. 2013, Wiseman et al. 2011). Stimulation of peroxynitrite degradation attenuates insulin resistance and improves insulin-stimulated glucose uptake in skeletal muscle in mice, suggesting that elevated peroxynitrite production during eccentric exercise might be at least partly responsible for the decrease in insulin sensitivity after exercise (Duplain et al. 2008, Lima-Cabello et al. 2010). Noteworthy, NO may play a very pleiotropic role in eccentric exercise beyond its role in insulin sensitivity. First, increased quantities of NO may stimulate nociceptors, contributing to the characteristic muscle soreness accompanying this type of exercise (Radak et al.
2012). Second, NO was shown to regulate force generation by reversibly inhibiting cytochrome oxidase, which affects oxygen uptake, therefore decreasing the maximal force production and protecting the already damaged muscle (Finocchietto et al. 2009). Third, exercise induced generation of $\mathrm{NO}$ is an important signal for interleukin-6, interleukin-8, hem oxygenase and HSP78 production (Klarlund Pedersen et al. 2001, Steensberg et al. 2007), and specifically, sarcolemmal neuronal nitric oxide synthase (nNOS) is an important regulator of blood flow to active skeletal muscle (Vincent et al. 2014). Last but not least, NO also plays crucial roles in muscle growth and regeneration as an activator of satellite cells (Yin et al. 2013) as well as a controller of the IGF-I/p70 S6 kinase signaling pathway (Sellman et al. 2006). All these roles of NO should be kept in mind when devising therapeutic strategies to influence its signaling (Aguiar et al. 2017).

However, a very recent experimental study of isolated rat muscle showed that the negative metabolic effect of eccentric exercise in terms of glucose uptake is limited to damaging eccentric exercise and does not occur after moderate eccentric exercise. It is also transient in nature and probably limited in time to the period immediately after the exercise and up to 48-hours postexercise. Finally, and most importantly, only insulindependent uptake seems to be affected by EIMD, not contraction-dependent glucose uptake. Interestingly, the contraction-dependent glucose uptake increased more immediately after damaging eccentric than after moderate eccentric, concentric, or isometric exercise, suggesting that some factor related to muscle damage is also a strong stimulant of contraction-induced glucose uptake. In fact, this increase might at least partly mitigate the reduction in insulin-dependent uptake (Andersen et al. 2019). These findings at the cellular level are complemented by exercise studies. In both healthy young females and males, as well as in prediabetic patients, non-damaging acute eccentric exercise has energy expendituredependent positive effects on insulin sensitivity and glucose tolerance, comparable with the effects of concentric exercise (Philippe et al. 2016b, 2016a, 2017). Moreover, acute anti-inflammatory effects through IL-6 may be even more pronounced by such non-damaging eccentric exercise than after concentric exercise matched for energy expenditure (Philippe et al. 2016b, 2016a). Finally, a small degree of EIMD was recently shown to not affect the insulin response and glucose tolerance immediately after eccentric exercise (Cook et al. 2015). 
Alone or combined, all of the above factors can contribute to an impaired whole-body insulin sensitivity and should be considered. A damaging eccentric exercise of even a small muscle group, such as isolated upper limb muscles, e.g., elbow flexors of only one arm, results in impaired whole-body insulin sensitivity. However, this is the case after the first but not after the second bout of exercise (Gonzalez et al. 2015). Conceivably, the impairment in insulin sensitivity is especially prominent if the muscle mass enrolled in eccentric exercise is larger and exercise is unaccustomed, but also in this case, the effect is abolished after multiple exercise bouts (Green et al. 2010, Paschalis et al. 2011, Vermaas and Runhaar 2011). From the available evidence, it seems that the long-term beneficial effects of eccentric exercise outweigh the transient negative effects on insulin sensitivity, but further studies are needed to resolve this issue.

\subsection{Clinical consequences of EIMD}

Ideally, muscle biopsy can serve as a direct marker for the degree of muscle damage. But to gain a precise insight into the time course of changes in the muscle, one would have to perform the biopsy multiple times and possibly at the same site, which is highly impractical if not impossible because of inflammation due to the biopsy itself (Brentano and Martins Kruel 2011, Damas et al. 2018, Malm 2001). Fortunately, many other more easily measurable consequences accompany muscle damage and can be used as practical indirect markers for EIMD. The markers most commonly used in the clinical environment are presented in detail below and their time courses are illustrated in Figure 3.

\subsubsection{Strength loss}

Strength loss is considered as the most reliable indirect marker of EIMD and is measured as a decrease in the rate of force development (RFD) and maximal voluntary contraction (MVC) torque (Damas et al. 2016, Peñailillo et al. 2015, Szczyglowski et al. 2017). By definition, in mild EIMD the reduction of MVC is less than $20 \%$, with few or absent morphological abnormalities and a full strength recovery within 48 hours. The MVC reduction of $20-50 \%$ is characteristic of moderate EIMD and is associated with mild inflammation, some myofibrillar disruption, and recovery time of up to 7 days. In severe EIMD, characterized by a greater than $50 \%$ MVC reduction, tissue damage is so profound that it can take weeks to recover (Raastad et al. 2010). Interestingly, strength restoration is accompanied by worsening of ultrastructural damage, confirming that apart from physical damage, defective excitation-contraction coupling (ECC), metabolic, and other changes described in previous chapters are involved in strength loss (Clarkson and Hubal 2002). When measuring muscle strength over the first 24 hours after eccentric exercise, a first decrease in strength is observed immediately post-exercise, followed by a gradual improvement over the next 4 hours. The second strength decrease ensues at 20-24-hours postexercise, most probably due to additional damage by inflammation or due to central inhibition by pain (Clarkson and Hubal 2002, MacIntyre et al. 1996, McKune et al. 2012). In quantitative terms, only approximately $25 \%$ of strength loss during the first 3 days of EIMD is believed to be a direct consequence of mechanical factors and the remaining $75 \%$ are probably due to the impaired ECC (Warren et al. 2002). Strength loss in the period beyond the first 3 days is most probably due to calpain-mediated contractile protein degradation (Murphy et al. 2013, Warren et al. 2002).

\subsubsection{Decreased range of motion}

Decreased range of motion (ROM) by up to 20-45 degrees immediately after eccentric exercise results from an inability to fully contract or fully extend the damaged muscle, and is a valid indicator of EIMD (McKune et al. 2012). The inability to fully contract might be due to overstretched sarcomeres or altered proprioception (Proske and Morgan 2001, Torres et al. 2010). The deficient contraction might ensue from supportive tissue damage, contractures, or swelling. Recovery typically starts within 24 hours (Clarkson et al. 1992).

\subsubsection{Swelling and hypertrophy}

As a rule, swelling and soreness are experienced on the day following eccentric exercise (Hough 1902). Edema and swelling begin to develop intramuscularly as soon as 0-1 hours post-exercise, then spread into the subcutaneous space (Clarkson 1997), and after a gradual increase peak at days 4-10 post-exercise. Intracellular edema has been reported to abate slowly, with persistent elevation in intracellular fluid detectable even after 2-3 months (Clarkson and Hubal 2002, Foley et al. 1999, McKune et al. 2012, Ploutz-Snyder et al. 1997).

Swelling is difficult to discern from hypertrophy as both processes increase muscle size. However, initial resistance training bouts more commonly increase muscle size due to swelling, while the advanced exercise bouts 


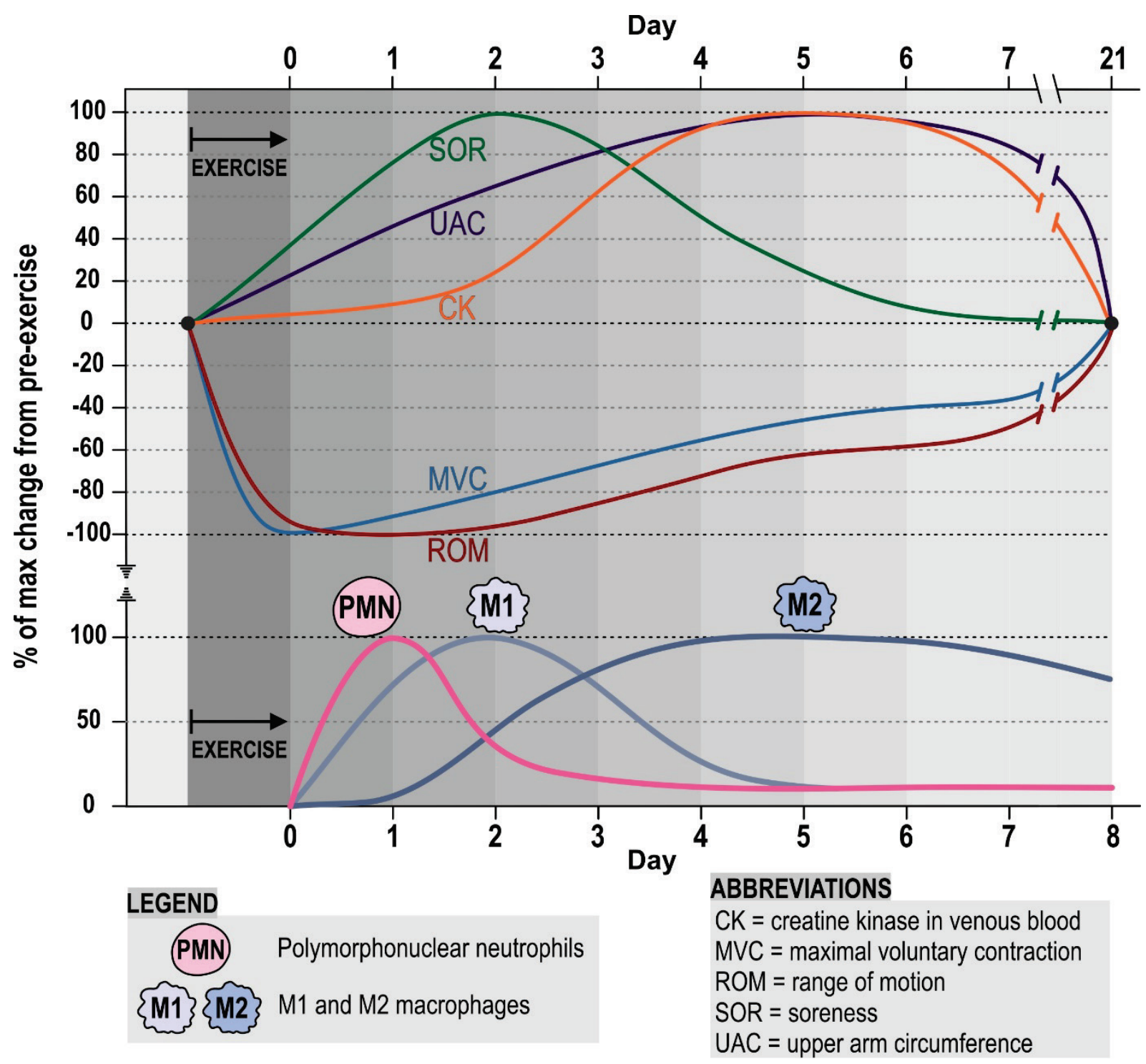

Fig. 3. Time course of relative changes in indirect EIMD markers (upper panel) and myeloid cell populations (lower panel) in muscle following EIMD. For each parameter, zero represents a value before exercise and $\pm 100 \%$ are representing relative maximum changes that were measured in different studies. Maximal voluntary contraction (MVC) torque represents strength loss. Muscle soreness (SOR) was evaluated with visual analogue scale. For analysis of creatine kinase (CK) activity, venous blood samples were collected. Range of motion (ROM) of the elbow joint was assessed with a goniometer. Measurements of upper arm circumference (UAC) quantitatively represent swelling. Data for the first 7 days are derived from 2 studies conducted on young men who performed 30 unaccustomed elbow flexor eccentric actions which resulted in $40 \%$ average decline in MVC from pre-exercise value of $100 \%$. Measurements were made before exercise, immediately after it and then once every 24 hours for 5 or 10 days (Chen and Nosaka 2006, Damas et al. 2016). To show schematically how the parameters normalize (days 7-21), data from other comparable studies were used, where unaccustomed elbow flexor eccentric actions also resulted in a 40-50 \% decline in MVC. This value corresponds to the upper limit of "moderate EIMD" (Foley et al. 1999, Jones et al. 1986, Paulsen et al. 2010). Note that 21 days is arbitrarily set as a safe time point by which all the parameters should reach their pre-exercise values in moderate EIMD (Paulsen et al. 2010). This time duration is shorter and longer in mild and severe EIMD, respectively and is certainly not the same for all parameters. Interestingly, it was suggested that UAC could even be negative 2-8 weeks post-exercise possibly due to a loss of vulnerable fibers (Foley et al. 1999). Finally, time points of maximum change were shown to be the same regardless of severity of EIMD (Clarkson et al. 1992, Foley et al. 1999, Lauritzen et al. 2009, Lavender and Nosaka 2008, Warren et al. 1999). In the lower panel, relative changes in myeloid cell populations in muscle following EIMD are shown. Approximately after 1-2 days after damaging exercise, polymorphonuclear neutrophils (PMN) and M1 macrophages are gradually being replaced by M2 macrophages, which probably serve a crucial role in muscle repair and remodeling (Tidball and Villalta 2010).

cause hypertrophy, characterized by contractile protein accumulation within 3-10 weeks (Counts et al. 2017, Damas et al. 2018). The exact role of muscle damage in hypertrophy remains to be elucidated (see below). It is possible that some extent of Z-band streaming is required to prepare muscle for hypertrophy by adding sarcomeres in series (remodeling) (Damas et al. 2018). Swelling and hypertrophy are usually assessed by measuring muscle 
group circumference or using ultrasonography and magnetic resonance imaging. However, none of the methods mentioned is able to distinguish between muscle swelling and hypertrophy. On the other hand, ultrasound echo intensity and MRI T2 relaxation time can offer a better estimate of edema-induced muscle swelling versus hypertrophy (Foley et al. 1999, McKune et al. 2012).

\subsubsection{Soreness}

Soreness, more commonly named delayed-onset muscle soreness (DOMS), typically appears 12-48 hours post-exercise, peaks at 24-72 hours, and subsides within 5-7 days (Guilhem et al. 2010b, McKune et al. 2012, Warren et al. 1999). Usually, DOMS is assessed by a visual analogue scale, and its manifestations include tenderness to palpitation, stretch, and contraction, as well as a dull pain of the entire muscle with possible aggravation at myotendinous junctions (Warren et al. 1999). Most probably, pain results from prostaglandins, histamine, and bradykinins as mediators of inflammation. They sensitize mechanical type III (type A $\delta$ ) and polymodal type IV (type C) nerve afferents and lower their activation threshold so that they respond to mechanical stimuli due to tissue swelling or to otherwise normal mechanical deformation (Clarkson and Hubal 2002, Clarkson and Sayers 1999, MacIntyre et al. 1995, Qamar et al. 2019). Nosaka and coworkers found that DOMS only poorly correlates with the extent of EIMD and inflammation (Nosaka et al. 2002).

\subsubsection{Increase of muscle proteins in plasma and other markers}

Intracellular muscle proteins can leak into the extracellular space after cell membrane damage. EIMD causes an increase in plasma myoglobin, creatine kinase, lactate dehydrogenase, myosin heavy chain, skeletal troponin I, alpha actin, fatty acid binding protein, aspartate aminotransferase, carbonic anhydrase II isoenzymes, and others (Brentano and Martins Kruel 2011). They are used as muscle damage biomarkers, but their concentrations strongly depend not only on their leakage from the damaged muscles but also on their removal rates. The most common and most sensitive marker used is creatine kinase, because of its relatively larger plasma concentration increase after EIMD and lower assay cost compared to other proteins (Sorichter et al. 1995). However, there are major considerations and limitations to its use as an EIMD marker. More specifically, there is a great concentration variability in creatine kinase among comparably trained individuals. The plasma concentration depends on exercise type and starts to increase only after approximately 12 -hours postexercise, peaking at 4-6 days (Fig. 3) (Chen et al. 2018, Damas et al. 2016). The total plasma concentration comprises various isoenzymes with different origins and the assay sensitivity and reproducibility are ambiguous (Clarkson and Hubal 2002). For early assessment of EIMD, skeletal troponin I, alpha actin, and fatty acid binding protein are more useful candidates (Gibala $e t$ al. 1995, Sorichter et al. 1997, 1998). Myoglobin and the n-terminal fragment of titin in urine could also be used as an alternative to plasma biomarkers of EIMD in the near future (Finsterer and Drory 2016, Jang et al. 2018, Kanda et al. 2017). Another noninvasive alternative for EIMD assessment is the analysis of saliva, in which proposed biomarkers include salivary immunoglobulins (in particular IgA), cortisol, testosterone, $\alpha$-amylase, lactoferrin, and others (Lindsay and Costello 2017, Papacosta and Nassis 2011). Infrared thermography has also been suggested for noninvasive detection of increased skin temperature as an indicator of EIMD (Hildebrandt et al. 2010). However, in at least one human study, skin temperature did not correlate with plasma creatine kinase and further studies could help clarify its applicability (Da Silva et al. 2018). Finally, oxidative stress indices, such as thiobarbituric acid reactive substances, protein carbonyls, and uric acid, are gaining importance as blood markers in human studies (Serravite et al. 2014).

\subsubsection{Increase of plasma proteins and extracellular dyes} in muscle

Apart from muscle proteins leaking into plasma after EIMD, protein flow also occurs in the inverse direction. Macromolecules normally found extracellularly, such as albumin, can enter muscle cells and be detected with immunohistochemical techniques. For research purposes, the Evans blue dye or horseradish peroxidase can be injected into the bloodstream and observed as an EIMD marker in muscle cells micro- or macroscopically (Hamer et al. 2002, McNeil and Khakee 1992). Noteworthy, Petrof and coworkers used the fluorescent dye procion orange in isolated muscles from control and $\mathrm{mdx}$ mice to show that dystrophin protects the plasma membrane from mechanical stress during eccentric contractions (Petrof et al. 1993). Safer alternative for membrane damage assessment and 
long-term studies including repeated biopsies, involves the identification of intracellular fibronectin using specific antibodies (Palacio et al. 2002).

\subsubsection{EMG changes}

Most of the methods of EIMD assessment mentioned in chapter 3.4.5 require blood sample analysis and are thus invasive and time consuming. As such, they are inappropriate either for frequent or fast EIMD monitoring. Alternatively, fast and painless evaluation of EIMD is achievable by surface electromyography (sEMG) in which the zero crossing rate (ZCR) and the AREA of integrated EMG were shown to be good predictors of muscle damage extent correlating well with CK measurements (Zhou et al. 2011). Furthermore, parameters described in section 3.2, such as the increase in EMG amplitude, increase in force fluctuations during sustained contraction, decreased conduction velocity, and others can be used to assess muscle damage (Semmler 2014, Semmler et al. 2007).

\subsection{The repeated bout effect}

A second bout of exercise similar to the one that elicited EIMD results in significantly less EIMD and substantially less pronounced consequences. It appears that this effect, coined the repeated bout effect, can be explained by neuromuscular, mechanical, and cellular adaptations (Hyldahl et al. 2017, Nosaka and Clarkson 1995). First, activation of a larger number of muscle fibers may redistribute the mechanical stress, such that the relative mechanical stress per myofibril is decreased (Hortobágyi et al. 1996). A very interesting confirmation that the activation patterns change comes from the fact that there is a crossover effect on the contralateral limb with ipsilateral training (Howatson and Van Someren 2007, Starbuck and Eston 2012). Mechanical adaptions involve increases in intramuscular connective tissue and intracellular non-contractile proteins, which provide reinforcement and dissipate the mechanical stress (Barash et al. 2002, Hyldahl and Hubal 2014, McHugh 2003). Cellular adaptations involve changes in the contractile machinery, proteolytic activity, and the inflammatory response (Douglas et al. 2017a, 2017b, Stupka et al. 2001, Tee et al. 2007). More specifically, the number of sarcomeres increases and the activity of neutrophils and monocytes decreases with repeated bouts (Franchi et al. 2017b, Guilhem et al. 2010a, Hyldahl et al. 2017, Morgan 1990, Pizza et al. 2002). Finally, it is worth pointing out that the repeated bout effect was typically described in cases of EIMD where the prevailing culprit is mechanical stress, i.e., in eccentric contraction, and that the adaptation may be less well pronounced in cases where metabolic stress is the predominant initiating factor for EIMD, i.e., in endurance training (Tee et al. 2007).

\subsection{The role of EIMD in hypertrophy and the risk of non-functional overreaching and overtraining}

One of the most striking examples of adaptation in human physiology is the skeletal muscle hypertrophy in response to resistance training, especially the one involving eccentric contraction (Egan and Zierath 2013, Franchi et al. 2017b, Rennie et al. 2004, Siriguleng et al. 2018). According to our current state of knowledge, both the exact hypertrophy stimulus and the hypertrophy sensors in skeletal muscle remain to be defined (Francaux and Deldicque 2019). However, mechanical load is likely the main stimulus and two Z-disk associated proteins, filamin-C and Bag3, are the most likely hypertrophy sensors (Rennie et al. 2004, Wackerhage et al. 2019). First, filamin-C, which is linked to the Z-disk, actin, and Bag3, become deformed under mechanical load. Second, both filamin-C and Bag 3 become phosphorylated during intense contractions by unknown kinases. When phosphorylated, Bag3 binds inhibitors of the mammalian target of rapamycin complex 1 (mTORC1) and of the Hippo effector Yap, as well as the autophagy-regulating synaptopodin-2 (Synpo2). In this way, mechanical load can disinhibit mTORC1-regulated protein synthesis and Yap-regulated branched-chain amino acid uptake, as well as activate Synpo2-regulated autophagy of damaged Z-disks, which is an essential part of muscle hypertrophy (Wackerhage et al. 2019). For excellent and exhaustive recent reviews of possible hypertrophy stimuli, sensors, and the signaling cascades, see Wackerhage et al. (2019), Egan and Zierath (2013), and Francaux and Deldicque (2019).

The role of EIMD in hypertrophy has been controversial since its proposal (Evans and Cannon 1991). The most important reason for this is that eccentric contraction produces higher loads, which are a more efficient direct hypertrophic stimulus, but it also increases the likelihood for EIMD. In other words, due to this confounding it is difficult to separate the effects of EIMD from other factors associated with eccentric contraction. However, evidence exists that muscle damage from other sources can induce hypertrophy and that satellite cells (SCs) probably play a central role in this case (Wackerhage et al. 2019). Moreover, SCs were shown to 
activate and proliferate in response to non-damaging exercise, but this response is stronger if the exercise is accompanied by EIMD (Crameri et al. 2004, 2007). Unfortunately, it remains to be resolved whether satellite cells contribute primarily to repair, remodeling, or also to hypertrophy. According to a recent view, SCs are certainly involved in repairing the muscle and remodeling of extracellular matrix following EIMD. With less damaging repeated bouts, their numbers remain elevated and enhance the myogenic capacity for future stressful events. They probably contribute new nuclei to myofibers only in cases of hypertrophy exceeding $25 \%$ of muscle volume (Damas et al. 2018).

Eccentric exercise protocols do not only cause EIMD and possibly hypertrophy, but can also result in performance decrease due to overreaching or overtraining if there is an imbalance between exercise sessions and recovery periods, as shown with specific overtraining protocols developed for mice (Pereira et al. 2012). Functional overreaching (FOR) is characterized by a short-term decrease followed by performance improvement after a few days of recovery. In nonfunctional overreaching (NFOR), performance is strongly impaired. There may be psychological or hormonal imbalances, as well as intramuscular and systemic inflammation requiring weeks or months to recover completely. The overtraining syndrome (OTS) can last months to years and the performance may never completely recover.

From a mechanistic point of view, da Rocha and colleagues have shown that in mice, an excessive downhill running protocol can inhibit muscle hypertrophy. It also caused some atrophy in the extensor digitorum longus (EDL) muscle consisting mainly of fast muscle fibers and induced endoplasmic reticulum stress in both fast and slow muscle types, which persisted even after the recovery period (Da Rocha et al. 2016, Pereira et al. 2016b). They also found micro-injuries with polymorphonuclear infiltrates in the soleus and EDL muscle, as well as significantly elevated pro-inflammatory cytokines IL-1 $\beta$ and IL-6 and the suppressor of cytokine signaling, SOCS-3, in mice overtrained by downhill running (Da Rocha et al. 2017). In addition, their histological analyses revealed macrophage and neutrophil infiltration in EDL muscle, but only macrophages in the soleus, suggesting that not all muscle types are affected equally by the same overtraining protocol (Da Rocha et al. 2017). Finally, overtraining by downhill running increased the percentage of type IIb muscle fibers in the soleus muscle which normally consists mostly of type I muscle fibers (Da Rocha et al. 2017). However, it did not cause sarcomerogenesis, i.e., an increase in sarcomere number in series or their length (Morais et al. 2020). Following 8 weeks of overtraining by downhill running, a 2-week recovery period upregulated the anti-inflammatory cytokines IL-10 and IL-15 and normalized the pro-inflammatory cytokines, but did not result in complete restoration of performance (Da Rocha et al. 2018).

In human studies, contrasting results were found regarding performance decrease after resistance training. Very recently, Grandou et al. systematically reviewed 22 studies on resistance exercise-overtraining, of which 12 studies reported decreased performance, while 10 of them showed no decrease in any measure of physical performance (Grandou et al. 2020). In 8 studies, the decreased performance returned to normal after 1-8 weeks of recovery, but in most of the studies, the performance testing during the follow-up period was inadequate to accurately diagnose FOR, NFOR or OTS. In summary, the underlying mechanisms of resistance exercise-induced overtraining remain unclear (Grandou et al. 2020). Another very recent review on FOR shows that similarly to resistance exercise-overtraining, some of the endurance athletes experience performance decrease after increased training intensity and/or volume, while others do not (Bellinger 2020). The most common model for inducing FOR and studying its consequences and recovery from overreaching typically employs an overtraining period of up to 4 weeks. When induced by such training intervention, FOR can have various cardiovascular consequences, such as reduced heart rate, stroke volume and cardiac output, increased parasympathetic heart rate modulation, and increased arterial stiffness. It is also typically accompanied by immunological consequences, such as compromised innate and/or adaptive immunity with decreased $\mathrm{CD} 20^{+}$ and neutrophil cell count, and increased incidence of illness. Finally, it can also reduce the resting metabolic rate, impair the quantity and quality of sleep, hinder exercise performance, and increase muscle soreness, as well as the subjective fatigue perception (Bellinger 2020). To avoid or at least diminish the risk of overtraining, some recommendations are given in chapter 3.8.

\subsection{The risk of EIMD in chronic diseases}

The exact mechanisms through which aerobic 
and resistance training can improve glycaemia and other metabolic parameters, as well as their effectiveness in improving performance and the health status of chronic patients are beyond the scope of this paper and have been excellently explained elsewhere (Hoppeler 2016, Milanović et al. 2015, Nakamoto and Ishihara 2020, Stanford and Goodyear 2014). Here, we would only like to point out that in one important respect, eccentric exercise seems especially promising for the elderly and clinical populations. Eccentric contraction is able to produce up to $60 \%$ higher forces at a lower energetic cost compared with concentric and isometric ones. Therefore, it elicits a much lower cardiopulmonary response (Douglas et al. 2017a, Franchi et al. 2017b, 2017a, Hoppeler 2016, Lastayo et al. 1999). For instance, up to 4-times less energy is required for walking downhill compared with going uphill over a given gradient (Hoppeler 2016). However, as EIMD impairs insulin sensitivity through oxidative stress and other mechanisms, recommending potentially damaging eccentric exercise to patients with insulin resistance and the metabolic syndrome has to be thoroughly considered. Especially because the levels of reactive species are already increased in these patients (Nomiyama et al. 2004, Schrauwen and Hesselink 2004, Torres et al. 2004). Importantly, deviations from normal weight in either direction increase an individual's susceptibility to EIMD (Paschalis et al. 2013). In the light of these potentially conflicting impacts on overall health, further studies are needed to clarify the benefits of acute and long-term exercise protocols, as well as eccentric compared to concentric resistance training and aerobic exercise protocols (Fischer et al. 2017, Roig et al. 2009). Since the incidence of associated cardiovascular diseases among diabetic patients is relatively high (Leon and Maddox 2015), they might not be capable of longduration, low-intensity aerobic exercise or high intensity eccentric resistance training. Until specific guidelines are available, eccentric exercise of low to mid intensity with gradual increase in intensity might be a reasonable alternative in such cases. Due to the repeated bout effect and otherwise superior hypertrophic effects of eccentric exercise, a single or a few episodes of mild EIMD seem like a risk that can be taken (Hody et al. 2019). Although here we focused on eccentric resistance exercise, it should be pointed out that a combination of aerobic and resistance exercise seems more effective in improving insulin sensitivity in patients with the metabolic syndrome than either modality alone (Colberg et al.
2010). Additionally, evidence is emerging that aerobic training may positively affect the hypertrophic response to resistance exercise and vice versa (Burt et al. 2015, Siriguleng et al. 2018).

\subsection{Some practical recommendations to avoid EIMD in athletes and patients}

To find a reasonable trade-off between the favorable effects of eccentric exercise and unwanted EIMD with its consequences, some important considerations must be taken into account when planning training regimes and performing exercises. It must be kept in mind that the risk for EIMD rises with eccentric torque, muscle length, and number of eccentric contractions (Nosaka and Newton 2002). The extent of damage also depends on muscle type, where upper limb muscles and knee flexors have been shown to be more susceptible to damage than lower limb muscles and knee extensors, respectively (Chen et al. 2011, Peñailillo et al. 2017).

LaStayo et al. propose an eccentric exposureadaptation phase with very light intensity as introduction to eccentric muscle training. After 2 weeks of performing such exercise 2-3 times per week in duration of 5-8 minutes per session, the muscle is prepared to resist progressively higher loads for prolonged periods in the so-called progressive eccentric-negative work phase. Eccentric exercise load should start to gradually exceed participant's isometric maximum load, with exercise duration being prolonged to 20-30 minutes per session, 2-3 times per week for 6-12 weeks (LaStayo et al. 2014). In accordance with the pathogenetic role of oxidative stress in EIMD, ischemic preconditioning may play a role in EIMD prevention in the future (Franz et al. 2017).

It should be pointed out that inappropriately high initial workloads can precipitate all the consequences of EIMD, which may disturb the progress of training. Patients in rehabilitation programs who experience severe DOMS do not adhere sufficiently to exercise programs. Similarly, trained athletes suffering from consequences of EIMD have worse performance in the short term, are unable to train at their maximal intensity, and have a higher risk of injuries, such as muscle tears or ligament ruptures. In this respect, athletes' muscles are especially vulnerable at the start of the season or when returning to perform following injury (Hody et al. 2019). For more specific and applicable guidelines, future research should clarify possible age- and sex-related differences in susceptibility to EIMD and its consequences. There is 
evidence suggesting that the susceptibility to EIMD increases with age (Chen et al. 2014, Deli et al. 2017). Additionally, women seem to be less susceptible to EIMD than men, and estrogen has been suggested to play a myoprotective role, although the available evidence does not universally support this view (Clarkson and Hubal 2002, Enns and Tiidus 2010, Hicks et al. 2016, Hubal et al. 2010, Minahan et al. 2015, Tiidus 2009, Tiidus and Enns 2009, Velders and Diel 2013). We finally wish to point out that there is a huge body of evidence for pharmacological and non-pharmacological means of preventing and treating EIMD that deserve separate reviews and are beyond the scope of our article (Harty et al. 2019, Howatson and Van Someren 2008, Owens et al. 2019, Peake et al. 2017a, 2017b).

\section{Conclusions}

Although EIMD has received a lot of attention over the last three decades and some mechanisms of its etiopathogenesis and consequences have been described, a number of questions remain to be answered. For instance, the relative contribution of mechanical and metabolic stress, as well as the roles played by inflammatory and satellite cells during different types of contraction remain to be defined. Moreover, the extraand intracellular signaling underlying EIMD, as well as the repeated bout effect and hypertrophy warrant further investigation. Elucidating these aspects shall further our understanding of normal muscle physiology and help us better understand the pathophysiology of clinically relevant genetic diseases. Finding new ways to detect and quantify the extent of EIMD noninvasively in the clinical setting will conceivably aid in diagnosing, tracking, and classifying different forms of EIMD. Together with a better understanding of genetic susceptibility to EIMD, this could pave the way to new and more personalized strategies for performance enhancement, individually tailored rehabilitation, prevention in chronic diseases, and treatment of muscular dystrophies.

\section{Conflict of Interest}

There is no conflict of interest.

\section{References}

AGUIAR AF, VECHETTI-JÚNIOR IJ, SOUZA RW, PIEDADE WP, PACAGNELLI FL, LEOPOLDO AS, CASONATTO J, DAL-PAI-SILVA M: Nitric oxide synthase inhibition impairs muscle regrowth following immobilization. 69: 22-27, 2017. https://doi.org/10.1016/j.niox.2017.07.006

AHLBORG G, FELIG P, HAGENFELDT L, HENDLER R, WAHREN J: Substrate turnover during prolonged exercise in man. Splanchnic and leg metabolism of glucose, free fatty acids, and amino acids. J Clin Invest 53: 10801090, 1974. https://doi.org/10.1172/JCI107645

AKIMOTO AK, MIRANDA-VILELA AL, ALVES PCZ, PEREIRA LCDS, LORDELO GS, HIRAGI CDO, DA SILVA ICR, GRISOLIA CK, KLAUTAU-GUIMARÃES MDN: Evaluation of gene polymorphisms in exercise-induced oxidative stress and damage. Free Radic Res 44: 322-331, 2010. https://doi.org/10.3109/10715760903494176

ALLEN D: Skeletal muscle function: Role of ionic changes in fatigue, damage and disease. Clin Exp Pharmacol Physiol 31: 485-493, 2004. https://doi.org/10.1111/j.1440-1681.2004.04032.x

ALLEN DG: Eccentric muscle damage: mechanisms of early reduction of force. Acta Physiol Scand 171: 311-319, 2001. https://doi.org/10.1046/j.1365-201x.2001.00833.x

ALLEN DG, GERVASIO OL, YEUNG EW, WHITEHEAD NP: Calcium and the damage pathways in muscular dystrophy. Can J Physiol Pharmacol 88: 83-91, 2010. https://doi.org/10.1139/Y09-058

ALLEN DG, WHITEHEAD NP, YEUNG EW: Mechanisms of stretch-induced muscle damage in normal and dystrophic muscle: Role of ionic changes. J Physiol 567: 723-735, 2005. https://doi.org/10.1113/jphysiol.2005.091694

ANDERSEN OE, NIELSEN OB, OVERGAARD K: Early effects of eccentric contractions on muscle glucose uptake. J Appl Physiol 126: 376-385, 2019. https://doi.org/10.1152/japplphysiol.00388.2018

ANDERSON EJ, NEUFER PD: Type II skeletal myofibers possess unique properties that potentiate mitochondrial $\mathrm{H}_{2} \mathrm{O}_{2}$ generation. Am J Physiol Physiol 290: C844-C851, 2006. https://doi.org/10.1152/ajpcell.00402.2005 
AOI W, NAITO Y, TOKUDA H, TANIMURA Y, OYA-ITO T, YOSHIKAWA T: Exercise-induced muscle damage impairs insulin signaling pathway associated with IRS-1 oxidative modification. Physiol Res 61: 81-88, 2012. https://doi.org/10.33549/physiolres.932239

AOI W, NAITO Y, YOSHIKAWA T: Role of oxidative stress in impaired insulin signaling associated with exerciseinduced muscle damage. Free Radic Biol Med 65: 1265-1272, 2013. https://doi.org/10.1016/j.freeradbiomed.2013.09.014

ARMSTRONG RB: Muscle Damage and Endurance Events. Sport Med 3: 370-381, 1986. https://doi.org/10.2165/00007256-198603050-00006

ARMSTRONG RB, WARREN GL, WARREN JA: Mechanisms of exercise-induced muscle fibre injury. Sport Med 12: 184-207, 1991. https://doi.org/10.2165/00007256-199112030-00004

ASP S, ROHDE T, RICHTER EA: Impaired muscle glycogen resynthesis after a marathon is not caused by decreased muscle GLUT-4 content. J Appl Physiol 83: 1482-1485, 1997. https://doi.org/10.1152/jappl.1997.83.5.1482

BALNAVE CD, ALLEN DG: Intracellular calcium and force in single mouse muscle fibres following repeated contractions with stretch. J Physiol 488: 25-36, 1995. https://doi.org/10.1113/jphysiol.1995.sp020943

BALNAVE CD, ALLEN DG: The effect of muscle length on intracellular calcium and force in single fibres from mouse skeletal muscle. J Physiol 492: 705-713, 1996. https://doi.org/10.1113/jphysiol.1996.sp021339

BALON TW, NADLER JL: Evidence that nitric oxide increases glucose transport in skeletal muscle. J Appl Physiol 82: 359-363, 1997. https://doi.org/10.1152/jappl.1997.82.1.359

BARASH IA, PETERS D, FRIDÉN J, LUTZ GJ, LIEBER RL: Desmin cytoskeletal modifications after a bout of eccentric exercise in the rat. Am J Physiol Integr Comp Physiol 283: R958-R963, 2002. https://doi.org/10.1152/ajpregu.00185.2002

BAUMERT P, G-REX CONSORTIUM, G-R, LAKE MJ, DRUST B, STEWART CE, ERSKINE RM, ADAMS B, CABOT JA, EDWARDS V, JOHNSON KO: TRIM63 (MuRF-1) gene polymorphism is associated with biomarkers of exercise-induced muscle damage. Physiol Genomics 50: 142-143, 2018a. https://doi.org/10.1152/physiolgenomics.00103.2017

BAUMERT P, LAKE MJ, STEWART CE, DRUST B, ERSKINE RM: Genetic variation and exercise-induced muscle damage: implications for athletic performance, injury and ageing. Eur J Appl Physiol 116: 1595-1625, 2016. https://doi.org/10.1007/s00421-016-3411-1

BAUMERT P, STEWART CE, LAKE MJ, DRUST B, ERSKINE RM: Variations of collagen-encoding genes are associated with exercise-induced muscle damage. Physiol Genomics 50: 691-693, $2018 \mathrm{~b}$. https://doi.org/10.1152/physiolgenomics.00145.2017

BEDAIR HS, KARTHIKEYAN T, QUINTERO A, LI Y, HUARD J: Angiotensin II receptor blockade administered after injury improves muscle regeneration and decreases fibrosis in normal skeletal muscle. Am J Sports Med 36: 1548-1554, 2008. https://doi.org/10.1177/0363546508315470

BEHRENS M, MAU-MOELLER A, BRUHN S: Effect of exercise-induced muscle damage on neuromuscular function of the quadriceps muscle. Int J Sports Med 33: 600-606, 2012. https://doi.org/10.1055/s-0032-1304642

BELCASTRO AN, SHEWCHUK LD, RAJ DA: Exercise-induced muscle injury: A calpain hypothesis. Mol Cell Biochem 179: 135-145, 1998. https://doi.org/10.1023/A:1006816123601

BELLINGER P: Functional overreaching in endurance athletes: a necessity or cause for concern? Sport Med 50: 1059-1073, 2020. https://doi.org/10.1007/s40279-020-01269-w

BRANCA D, GUGLIUCCI A, BANO D, BRINI M, CARAFOLI E: Expression, partial purification and functional properties of themuscle-specific calpain isoform p94. Eur J Biochem 265: 839-846, 1999. https://doi.org/10.1046/j.1432-1327.1999.00817.x

BRENTANO MA, MARTINS KRUEL LF: A review on strength exercise-induced muscle damage: Applications, adaptation mechanisms and limitations. J Sports Med Phys Fitness 51: 1-10, 2011.

BROOS S, MALISOUX L, THEISEN D, FRANCAUX M, DELDICQUE L, THOMIS MA: Role of Alpha-actinin-3 in contractile properties of human single muscle fibers: a case series study in paraplegics. PLoS One 7: e49281, 2012. https://doi.org/10.1371/journal.pone.0049281

BURESH R, BERG K: Exercise for the management of type 2 diabetes mellitus: Factors to consider with current guidelines. J Sports Med Phys Fitness 58: 510-524, 2018. 
BURT D, LAMB K, NICHOLAS C, TWIST C: Lower-volume muscle-damaging exercise protects against high-volume muscle-damaging exercise and the detrimental effects on endurance performance. Eur J Appl Physiol 115: 1523-1532, 2015. https://doi.org/10.1007/s00421-015-3131-y

CAUCI S, DI SANTOLO M, RYCKMAN KK, WILLIAMS SM, BANFI G: Variable number of tandem repeat polymorphisms of the interleukin-1 receptor antagonist gene IL-1RN: A novel association with the athlete status. BMC Med Genet 11, 2010. https://doi.org/10.1186/1471-2350-11-29

CHAZAUD B: Inflammation during skeletal muscle regeneration and tissue remodeling: application to exerciseinduced muscle damage management. Immunol Cell Biol 94: 140-145, 2016. https://doi.org/10.1038/icb.2015.97

CHEN B: Association between SLC30A8 rs13266634 polymorphism and type 2 diabetes risk: a meta-analysis. Med Sci Monit 21: 2178-2189, 2015. https://doi.org/10.12659/MSM.894052

CHEN TC, CHEN HL, LIU YC, NOSAKA K: Eccentric exercise-induced muscle damage of pre-adolescent and adolescent boys in comparison to young men. Eur J Appl Physiol 114: 1183-1195, 2014. https://doi.org/10.1007/s00421-014-2848-3

CHEN TC, LIN K-Y, CHEN H-L, LIN M-J, NOSAKA K: Comparison in eccentric exercise-induced muscle damage among four limb muscles. Eur J Appl Physiol 111: 211-223, 2011. https://doi.org/10.1007/s00421-010-1648-7

CHEN TC, LIN M-J, LAI J-H, CHEN H-L, YU H-I, NOSAKA K: Low-intensity elbow flexion eccentric contractions attenuate maximal eccentric exercise-induced muscle damage of the contralateral arm. J Sci Med Sport 21: 1068-1072, 2018. https://doi.org/10.1016/j.jsams.2017.12.012

CHEN TC, NOSAKA K: Effects of number of eccentric muscle actions on first and second bouts of eccentric exercise of the elbow flexors. J Sci Med Sport 9: 57-66, 2006. https://doi.org/10.1016/j.jsams.2006.03.012

CLARKSON P: Eccentric exercise and muscle damage. Int J Sports Med 18: S314-S317, 1997. https://doi.org/10.1055/s-2007-972741

CLARKSON PM, HOFFMAN EP, ZAMBRASKI E, GORDISH-DRESSMAN H, KEARNS A, HUBAL M, HARMON B, DEVANEY JM: ACTN3 and MLCK genotype associations with exertional muscle damage. J Appl Physiol 99: 564-569, 2005. https://doi.org/10.1152/japplphysiol.00130.2005

CLARKSON PM, HUBAL MJ: Exercise-induced muscle damage in humans. Am J Phys Med Rehabil 81: S52-S69, 2002. https://doi.org/10.1097/00002060-200211001-00007

CLARKSON PM, NOSAKA K, BRAUN B: Muscle function after exercise-induced muscle damage and rapid adaptation. Med Sci Sports Exerc 24: 512-520, 1992. https://doi.org/10.1249/00005768-199205000-00004

CLARKSON PM, SAYERS SP: Etiology of Exercise-Induced Muscle Damage. Can J Appl Physiol 24: 234-248, 1999. https://doi.org/10.1139/h99-020

CLOSE GL, ASHTON T, CABLE T, DORAN D, MACLAREN DPM: Eccentric exercise, isokinetic muscle torque and delayed onset muscle soreness: the role of reactive oxygen species. Eur J Appl Physiol 91: 615-621, 2004. https://doi.org/10.1007/s00421-003-1012-2

CODELLA R, TERRUZZI I, LUZI L: Why should people with type 1 diabetes exercise regularly? Acta Diabetol 54: 615-630, 2017. https://doi.org/10.1007/s00592-017-0978-x

COLBERG SR, SIGAL RJ, FERNHALL B, REGENSTEINER JG, BLISSMER BJ, RUBIN RR, CHASAN-TABER L, ALBRIGHT AL, BRAUN B, AMERICAN COLLEGE OF SPORTS MEDICINE, AMERICAN DIABETES ASSOCIATION: Exercise and type 2 diabetes: The American college of sports medicine and the American diabetes association: joint position statement. Diabetes Care 33: 2692-2696, 2010. https://doi.org/10.2337/dc10-1548

COOK MD, MYERS SD, KELLY JSM, WILLEMS MET: Acute postexercise effects of concentric and eccentric exercise on glucose tolerance. Int $\mathrm{J}$ Sport Nutr Exerc Metab 25: 14-19, 2015. https://doi.org/10.1123/ijsnem.2013-0261

CORONA BT, BALOG EM, DOYLE JA, RUPP JC, LUKE RC, INGALLS CP: Junctophilin damage contributes to early strength deficits and EC coupling failure after eccentric contractions. Am J Physiol Physiol 298: C365-C376, 2010. https://doi.org/10.1152/ajpcell.00365.2009

COUNTS BR, BUCKNER SL, MOUSER JG, DANKEL SJ, JESSEE MB, MATTOCKS KT, LOENNEKE JP: Muscle growth: To infinity and beyond? Muscle Nerve 56: 1022-1030, 2017. https://doi.org/10.1002/mus.25696 
CRAMERI RM, AAGAARD P, QVORTRUP K, LANGBERG H, OLESEN J, KJÆR M: Myofibre damage in human skeletal muscle: Effects of electrical stimulation versus voluntary contraction. J Physiol 583: 365-380, 2007. https://doi.org/10.1113/jphysiol.2007.128827

CRAMERI RM, LANGBERG H, MAGNUSSON P, JENSEN CH, SCHRØODER HD, OLESEN JL, SUETTA C, TEISNER B, KJAER M: Changes in satellite cells in human skeletal muscle after a single bout of high intensity exercise. J Physiol 558: 333-340, 2004. https://doi.org/10.1113/jphysiol.2004.061846

CRANE JD, ABADI A, HETTINGA BP, OGBORN DI, MACNEIL LG, STEINBERG GR, TARNOPOLSKY MA: Elevated mitochondrial oxidative stress impairs metabolic adaptations to exercise in skeletal muscle. PLoS One 8, 2013. https://doi.org/10.1371/journal.pone.0081879

DA ROCHA AL, PEREIRA BC, PAULI JR, DE SOUZA CT, TEIXEIRA GR, LIRA FS, CINTRA DE, ROPELLE ER, JÚNIOR CRB, DA SILVA ASR: Downhill running excessive training inhibits hypertrophy in mice skeletal muscles with different fiber type composition. J Cell Physiol 231: 1045-1056, 2016. https://doi.org/10.1002/jcp.25197

DA ROCHA AL, PEREIRA BC, TEIXEIRA GR, PINTO AP, FRANTZ FG, ELIAS LLK, LIRA FS, PAULI JR, CINTRA DE, ROPELLE ER, DE MOURA LP, MEKARY RA, DE FREITAS EC, DA SILVA ASR: Treadmill slope modulates inflammation, fiber type composition, androgen, and glucocorticoid receptors in the skeletal muscle of overtrained mice. Front Immunol 8, 2017. https://doi.org/10.3389/fimmu.2017.01378

DA ROCHA AL, PINTO AP, PEREIRA BC, KOHAMA EB, MORAIS GP, DE VICENTE LG, PAULI JR, CINTRA DE, ROPELLE ER, DE MOURA LP, FILHO HT, DA SILVA ASR: Positive effects of total recovery period on anti- and pro-inflammatory cytokines are not linked to performance re-establishment in overtrained mice. Cytokine 103: 69-76, 2018. https://doi.org/10.1016/j.cyto.2018.01.005

DA SILVA W, MACHADO ÁS, SOUZA MA, KUNZLER MR, PRIEGO-QUESADA JI, CARPES FP: Can exerciseinduced muscle damage be related to changes in skin temperature? Physiol Meas 39: 104007, 2018. https://doi.org/10.1088/1361-6579/aae6df

DAMAS F, LIBARDI CA, UGRINOWITSCH C: The development of skeletal muscle hypertrophy through resistance training: the role of muscle damage and muscle protein synthesis. Eur J Appl Physiol 118: 485-500, 2018. https://doi.org/10.1007/s00421-017-3792-9

DAMAS F, NOSAKA K, LIBARDI C, CHEN T, UGRINOWITSCH C: Susceptibility to exercise-induced muscle damage: a cluster analysis with a large sample. Int J Sports Med 37: 633-640, 2016. https://doi.org/10.1055/s0042-100281

DARTNALL TJ, NORDSTROM MA, SEMMLER JG: Motor unit synchronization is increased in biceps brachii after exercise-induced damage to elbow flexor muscles. J Neurophysiol 99: 1008-1019, 2008. https://doi.org/10.1152/jn.00686.2007

DARTNALL TJ, NORDSTROM MA, SEMMLER JG: Adaptations in biceps brachii motor unit activity after repeated bouts of eccentric exercise in elbow flexor muscles. J Neurophysiol 105: 1225-1235, 2011. https://doi.org/10.1152/jn.00854.2010

DEFRONZO RA, FERRANNINI E, GROOP L, HENRY RR, HERMAN WH, HOLST JJ, HU FB, KAHN CR, RAZ I, SHULMAN GI, SIMONSON DC, TESTA MA, WEISS R: Type 2 diabetes mellitus. Nat Rev Dis Prim 1: 15019, 2015. https://doi.org/10.1038/nrdp.2015.19

DEFRONZO RA, JACOT E, JEQUIER E, MAEDER E, WAHREN J, FELBER JP: The effect of insulin on the disposal of intravenous glucose: results from indirect calorimetry and hepatic and femoral venous catheterization. Diabetes 30: 1000-1007, 1981. https://doi.org/10.2337/diab.30.12.1000

DELI CK, FATOUROS IG, PASCHALIS V, GEORGAKOULI K, ZALAVRAS A, AVLONITI A, KOUTEDAKIS Y, JAMURTAS AZ: A comparison of exercise-induced muscle damage following maximal eccentric contractions in men and boys. Pediatr Exerc Sci 29: 316-325, 2017. https://doi.org/10.1123/pes.2016-0185

DOBROWOLNY G, GIACINTI C, PELOSI L, NICOLETTI C, WINN N, BARBERI L, MOLINARO M, ROSENTHAL N, MUSARÒ A: Muscle expression of a local Igf-1 isoform protects motor neurons in an ALS mouse model. J Cell Biol 168: 193-199, 2005. https://doi.org/10.1083/jcb.200407021

DOUGLAS J, PEARSON S, ROSS A, MCGUIGAN M: Eccentric exercise: physiological characteristics and acute responses. Sport Med 47: 663-675, 2017a. https://doi.org/10.1007/s40279-016-0624-8 
DOUGLAS J, PEARSON S, ROSS A, MCGUIGAN M: Chronic adaptations to eccentric training: a systematic review. Sport Med 47: 917-941, 2017b. https://doi.org/10.1007/s40279-016-0628-4

DUAN C, DELP MD, HAYES DA, DELP PD, ARMSTRONG RB: Rat skeletal muscle mitochondrial $\left[\mathrm{Ca}^{2+}\right]$ and injury from downhill walking. J Appl Physiol 68: 1241-1251, 1990. https://doi.org/10.1152/jappl.1990.68.3.1241

DUAN C, REN H, GAO S: Insulin-like growth factors (IGFs), IGF receptors, and IGF-binding proteins: Roles in skeletal muscle growth and differentiation. Gen Comp Endocrinol 167: 344-351, 2010. https://doi.org/10.1016/j.ygcen.2010.04.009

DUNCAN CJ: Role of intracellular calcium in promoting muscle damage: A strategy for controlling the dystrophic condition. Experientia 34: 1531-1535, 1978. https://doi.org/10.1007/BF02034655

DUNDON JM, CIRILLO J, SEMMLER JG: Low-frequency fatigue and neuromuscular performance after exerciseinduced damage to elbow flexor muscles. J Appl Physiol 105: 1146-1155, 2008. https://doi.org/10.1152/japplphysiol.01339.2007

DUPLAIN H, SARTORI C, DESSEN P, JAYET P-Y, SCHWAB M, BLOCH J, NICOD P, SCHERRER U: Stimulation of peroxynitrite catalysis improves insulin sensitivity in high fat diet-fed mice. J Physiol 586: 4011-4016, 2008. https://doi.org/10.1113/jphysiol.2008.154302

EGAN B, ZIERATH JR: Exercise metabolism and the molecular regulation of skeletal muscle adaptation. Cell Metab 17: 162-184, 2013. https://doi.org/10.1016/j.cmet.2012.12.012

ENNS DL, TIIDUS PM: The influence of estrogen on skeletal muscle. Sport Med 40: 41-58, 2010. https://doi.org/10.2165/11319760-000000000-00000

ERSKINE RM, WILLIAMS AG, JONES DA, STEWART CE, DEGENS H: The individual and combined influence of ACE and ACTN3 genotypes on muscle phenotypes before and after strength training. Scand J Med Sci Sport 24: 642-648, 2014. https://doi.org/10.1111/sms.12055

EVANS PL, MCMILLIN SL, WEYRAUCH LA, WITCZAK CA: Regulation of skeletal muscle glucose transport and glucose metabolism by exercise training. Nutrients 11: 2432, 2019. https://doi.org/10.3390/nu11102432

EVANS WJ, CANNON JG: The metabolic effects of exercise-induced muscle damage. Exerc Sport Sci Rev 19: 99125, 1991. https://doi.org/10.1249/00003677-199101000-00003

FABIATO BYA, FABIATO F: Effects of $\mathrm{pH}$ on the myofilaments and the sarcoplasmic reticulum of skinned cells from cardiace and skeletal muscles. J Physiol 276: 233-255, 1978. https://doi.org/10.1113/jphysiol.1978.sp012231

FATOUROS IG, JAMURTAS AZ: Insights into the molecular etiology of exercise-induced inflammation: Opportunities for optimizing performance. Dovepress 2016, pp 175-186. https://doi.org/10.2147/JIR.S114635

FAULKNER JA: Terminology for contractions of muscles during shortening, while isometric, and during lengthening. J Appl Physiol 95: 455-459, 2003. https://doi.org/10.1152/japplphysiol.00280.2003

FINOCCHIETTO PV, FRANCO MC, HOLOD S, GONZALEZ AS, CONVERSO DP, ARCIUCH VGA, SERRA MP, PODEROSO JJ, CARRERAS MC: Mitochondrial nitric oxide synthase: a masterpiece of metabolic adaptation, cell growth, transformation, and death. Exp Biol Med 234: 1020-1028, 2009. https://doi.org/10.3181/0902MR-81

FINSTERER J, DRORY VE: Wet, volatile, and dry biomarkers of exercise-induced muscle fatigue. BMC Musculoskelet Disord 17: 40, 2016. https://doi.org/10.1186/s12891-016-0869-2

FISCHER SM, STAVRES J, MCDANIEL J: Metabolic differences between a bout of eccentric, concentric and traditional resistance exercise. Med Sci Sport Exerc 49: 272-273, 2017. https://doi.org/10.1249/01.mss.0000517603.70626.5a

FOLEY JM, JAYARAMAN RC, PRIOR BM, PIVARNIK JM, MEYER RA: MR measurements of muscle damage and adaptation after eccentric exercise. J Appl Physiol 87: 2311-2318, 1999. https://doi.org/10.1152/jappl.1999.87.6.2311

FOLKESSON M, MACKEY AL, LANGBERG H, OSKARSSON E, PIEHL-AULIN K, HENRIKSSON J, KADI F: The expression of heat shock protein in human skeletal muscle: Effects of muscle fibre phenotype and training background. Acta Physiol 209: 26-33, 2013. https://doi.org/10.1111/apha.12124

FRANCAUX M, DELDICQUE L: Exercise and the control of muscle mass in human. Pflügers Arch - Eur J Physiol 471: 397-411, 2019. https://doi.org/10.1007/s00424-018-2217-x 
FRANCHI M V, MITCHELL KW, HOPPELER H, NARICI M V: Editorial: Physiology and clinical potential of eccentric exercise. Front Physiol 8: 2017a. https://doi.org/10.3389/fphys.2017.00891

FRANCHI M V, REEVES ND, NARICI MV: Skeletal muscle remodeling in response to eccentric vs. concentric loading: morphological, molecular, and metabolic adaptations. Front Physiol 8: 447, $2017 \mathrm{~b}$. https://doi.org/10.3389/fphys.2017.00447

FRANZ A, BEHRINGER M, NOSAKA K, BUHREN BA, SCHRUMPF H, MAYER C, ZILKENS C, SCHUMANN $\mathrm{M}$ : Mechanisms underpinning protection against eccentric exercise-induced muscle damage by ischemic preconditioning. Med Hypotheses 98: 21-27, 2017. https://doi.org/10.1016/j.mehy.2016.11.008

FRIDÉN J, SJÖSTRÖM M, EKBLOM B: A morphological study of delayed muscle soreness. Experientia 37: 506-507, 1981. https://doi.org/10.1007/BF01986165

GAILLY P: TRP channels in normal and dystrophic skeletal muscle. Curr Opin Pharmacol 12: 326-334, 2012. https://doi.org/10.1016/j.coph.2012.01.018

GAO QQ, MCNALLY EM: The dystrophin complex: Structure, function, and implications for therapy. Compr Physiol 5: 1223-1239, 2015. https://doi.org/10.1002/cphy.c140048

GAVIN JP, MYERS SD, WILLEMS ME: Cardiorespiratory and metabolic responses after exercise-induced muscle damage: The influence of lowered glycogen. J Sports Med Phys Fitness 58: 332-340, 2018.

GIBALA MJ, MACDOUGALL JD, TARNOPOLSKY MA, STAUBER WT, ELORRIAGA A: Changes in human skeletal muscle ultrastructure and force production after acute resistance exercise. J Appl Physiol 78: 702-708, 1995. https://doi.org/10.1152/jappl.1995.78.2.702

GOLL DE, THOMPSON VF, LI H, WEI W, CONG J: The calpain system. Physiol Rev 83: 731-801, 2003. https://doi.org/10.1152/physrev.00029.2002

GONZALEZ JT, BARWOOD MJ, GOODALL S, THOMAS K, HOWATSON G: Alterations in whole-body insulin sensitivity resulting from repeated eccentric exercise of a single muscle group: A pilot investigation. Int J Sport Nutr Exerc Metab 25: 405-410, 2015. https://doi.org/10.1123/ijsnem.2014-0211

GOODYEAR, PHD LJ, KAHN, MD BB: Exercise, glucose transport, and insulin sensitivity. Annu Rev Med 49: 235-261, 1998. https://doi.org/10.1146/annurev.med.49.1.235

GRANDOU C, WALLACE L, IMPELLIZZERI FM, ALLEN NG, COUTTS AJ: Overtraining in resistance exercise: an exploratory systematic review and methodological appraisal of the literature. Sport Med 50: 815-828, 2020. https://doi.org/10.1007/s40279-019-01242-2

GREEN MS, DOYLE JA, INGALLS CP, BENARDOT D, RUPP JC, CORONA BT: Adaptation of insulin-resistance indicators to a repeated bout of eccentric exercise in human skeletal muscle. Int J Sport Nutr Exerc Metab 20: 181-190, 2010. https://doi.org/10.1123/ijsnem.20.3.181

GUHARAY F, SACHS F: Stretch-activated single ion channel currents in tissue-cultured embryonic chick skeletal muscle. J Physiol 352: 685-701, 1984. https://doi.org/10.1113/jphysiol.1984.sp015317

GUILHEM G, CORNU C, GUÉVEL A: Neuromuscular and muscle-tendon system adaptations to isotonic and isokinetic eccentric exercise Adaptations neuromusculaires et musculo-tendineuses à l'exercice excentrique isotonique et isocinétique. Ann Phys Rehabil Med 53: 319-341, 2010a. https://doi.org/10.1016/j.rehab.2010.04.003

GUILHEM G, CORNU C, GUÉVEL A: Adaptations neuromusculaires et musculo-tendineuses à l'exercice excentrique isotonique et isocinétique. Ann Phys Rehabil Med 53: 319-341, $2010 \mathrm{~b}$. https://doi.org/10.1016/j.rehab.2010.04.003

HAMER PW, MCGEACHIE JM, DAVIES MJ, GROUNDS MD: Evans Blue Dye as an in vivo marker of myofibre damage: optimising parameters for detecting initial myofibre membrane permeability. J Anat 200: 69-79, 2002. https://doi.org/10.1046/j.0021-8782.2001.00008.x

HANSEN M, BOESEN A, HOLM L, FLYVBJERG A, LANGBERG H, KJAER M: Local administration of insulinlike growth factor-I (IGF-I) stimulates tendon collagen synthesis in humans. Scand J Med Sci Sport 23: 614-619, 2013. https://doi.org/10.1111/j.1600-0838.2011.01431.x

HARTY PS, COTTET ML, MALLOY JK, KERKSICK CM: Nutritional and supplementation strategies to prevent and attenuate exercise-induced muscle damage: a brief review. Sport Med - Open 5: 1-17, 2019. https://doi.org/10.1186/s40798-018-0176-6 
HAYASHI T, WOJTASZEWSKI JF, GOODYEAR LJ: Exercise regulation of glucose transport in skeletal muscle. Am J Physiol 273: E1039-51, 1997. https://doi.org/10.1152/ajpendo.1997.273.6.E1039

HEDAYATPOUR N, FALLA D, ARENDT-NIELSEN L, VILA-CHÃ C, FARINA D: Motor unit conduction velocity during sustained contraction after eccentric exercise. Med Sci Sports Exerc 41: 1927-1933, 2009. https://doi.org/10.1249/MSS.0b013e3181a3a505

HEINEMEIER KM, BJERRUM SS, SCHJERLING P, KJAER M: Expression of extracellular matrix components and related growth factors in human tendon and muscle after acute exercise. Scand J Med Sci Sport 23: 150-161, 2013. https://doi.org/10.1111/j.1600-0838.2011.01414.x

HENNIGAR SR, MCCLUNG JP, PASIAKOS SM: Nutritional interventions and the IL-6 response to exercise. FASEB J 31: 3719-3728, 2017. https://doi.org/10.1096/fj.201700080R

HICKS KM, ONAMBÉLÉ GL, WINWOOD K, MORSE CI: Muscle Damage following Maximal Eccentric Knee Extensions in Males and Females. PLoS One 11: e0150848, 2016. https://doi.org/10.1371/journal.pone.0150848

HIGAKI Y, HIRSHMAN MF, FUJII N, GOODYEAR LJ: Nitric oxide increases glucose uptake through a mechanism that is distinct from the insulin and contraction pathways in rat skeletal muscle. Diabetes 50: 241-7, 2001. https://doi.org/10.2337/diabetes.50.2.241

HIGAKI Y, MIKAMI T, FUJII N, HIRSHMAN MF, KOYAMA K, SEINO T, TANAKA K, GOODYEAR LJ: Oxidative stress stimulates skeletal muscle glucose uptake through a phosphatidylinositol 3-kinase-dependent pathway. Am J Physiol Endocrinol Metab 294: 889-897, 2008. https://doi.org/10.1152/ajpendo.00150.2007

HILDEBRANDT C, RASCHNER C, AMMER K: An overview of recent application of medical infrared thermography in sports medicine in Austria. 10: 4700-4715, 2010. https://doi.org/10.3390/s100504700

HODY S, CROISIER JL, BURY T, ROGISTER B, LEPRINCE P: Eccentric muscle contractions: Risks and benefits. Front Physiol 10, 2019. https://doi.org/10.3389/fphys.2019.00536

HOPPELER H: Moderate load eccentric exercise, a distinct novel training modality. Front Physiol 7: 483, 2016. https://doi.org/10.3389/fphys.2016.00483

HORTOBÁGYI T, BARRIER J, BEARD D, BRASPENNINCX J, KOENS P, DEVITA P, DEMPSEY L, LAMBERT J: Greater initial adaptations to submaximal muscle lengthening than maximal shortening. J Appl Physiol 81: 1677-82, 1996. https://doi.org/10.1152/jappl.1996.81.4.1677

HOUGH T: Ergographic Studies in Muscular Soreness. Am J Physiol 7: 76-92, 1902. https://doi.org/10.1152/ajplegacy.1902.7.1.76

HOWATSON G, VAN SOMEREN KA: Repeated bout effect after maximal eccentric contractions. Eur J Appl Physiol 101: 207-214, 2007. https://doi.org/10.1007/s00421-007-0489-5

HOWATSON G, VAN SOMEREN KA: The prevention and treatment of exercise-induced muscle damage. Sport Med 38: 483-503, 2008. https://doi.org/10.2165/00007256-200838060-00004

HOWELL JN, CHLEBOUN G, CONATSER R: Muscle stiffness, strength loss, swelling and soreness following exercise-induced injury in humans. J Physiol 1993. https://doi.org/10.1113/jphysiol.1993.sp019629

HSU M-F, PAN K-T, CHANG F-Y, KHOO K-H, URLAUB H, CHENG C-F, CHANG G-D, HAJ FG, MENG T-C: S-nitrosylation of endogenous protein tyrosine phosphatases in endothelial insulin signaling. Free Radic Biol Med 99: 199-213, 2016. https://doi.org/10.1016/j.freeradbiomed.2016.08.012

HUANG J, ZHU X: The molecular mechanisms of calpains action on skeletal muscle atrophy. Physiol Res 65: 547-560, 2016. https://doi.org/10.33549/physiolres.933087

HUBAL MJ, DEVANEY JM, HOFFMAN EP, ZAMBRASKI EJ, GORDISH-DRESSMAN H, KEARNS AK, LARKIN JS, ADHAM K, PATEL RR, CLARKSON PM: CCL2 and CCR2 polymorphisms are associated with markers of exercise-induced skeletal muscle damage. J Appl Physiol 108: 1651-1658, 2010. https://doi.org/10.1152/japplphysiol.00361.2009

HUGHES J, CHAPMAN P, BROWN S, JOHNSON N, STANNARD S: Indirect measures of substrate utilisation following exercise-induced muscle damage. Eur J Sport Sci 13: 509-517, 2013. https://doi.org/10.1080/17461391.2012.755570

HYLDAHL RD, CHEN TC, NOSAKA K: Mechanisms and mediators of the skeletal muscle repeated bout effect. Exerc Sport Sci Rev 45: 24-33, 2017. https://doi.org/10.1249/JES.0000000000000095 
HYLDAHL RD, HUBAL MJ: Lengthening our perspective: Morphological, cellular, and molecular responses to eccentric exercise. 49: 155-170, 2014. https://doi.org/10.1002/mus.24077

HYLDAHL RD, SCHWARTZ LM, CLARKSON PM: NF-KB activity functions in primary pericytes in a cell- and non-cell-autonomous manner to affect myotube formation. 47: 522-531, 2013. https://doi.org/10.1002/mus.23640

HYLDAHL RD, XIN L, HUBAL MJ, MOECKEL-COLE S, CHIPKIN S, CLARKSON PM: Activation of nuclear factor- $\mathrm{KB}$ following muscle eccentric contractions in humans is localized primarily to skeletal muscle-residing pericytes. FASEB J 25: 2956-2966, 2011. https://doi.org/10.1096/fj.10-177105

JANG H-J, LEE JD, JEON H-S, KIM A-R, KIM S, LEE H-S, KIM K-B: Metabolic profiling of eccentric exerciseinduced muscle damage in human urine. Toxicol Res 34: 199-210, 2018. https://doi.org/10.5487/TR.2018.34.3.199

JENSEN TE, SYLOW L, ROSE AJ, MADSEN AB, ANGIN Y, MAARBJERG SJ, RICHTER EA: Contractionstimulated glucose transport in muscle is controlled by AMPK and mechanical stress but not sarcoplasmatic reticulum Ca 2+ release. Mol Metab 3: 742-753, 2014. https://doi.org/10.1016/j.molmet.2014.07.005

JENTJENS R, JEUKENDRUP AE: Determinants of post-exercise glycogen synthesis during short-term recovery. Sport Med 33: 117-144, 2003. https://doi.org/10.2165/00007256-200333020-00004

JIAO S, REN H, LI Y, ZHOU J, DUAN C, LU L: Differential regulation of IGF-I and IGF-II gene expression in skeletal muscle cells. Mol Cell Biochem 373: 107-113, 2013. https://doi.org/10.1007/s11010-012-1479-4

JONES DA, NEWHAM DJ, CLARKSON PM: Skeletal muscle stiffness and pain following eccentric exercise of the elbow flexors. Pain 30: 233-242, 1987. https://doi.org/10.1016/0304-3959(87)91079-7

JONES DA, NEWHAM DJ, ROUND JM, TOLFREE SE: Experimental human muscle damage: morphological changes in relation to other indices of damage. J Physiol 375: 435-448, 1986. https://doi.org/10.1113/jphysiol.1986.sp016126

KANDA K, SAKUMA J, AKIMOTO T, KAWAKAMI Y, SUZUKI K: Detection of titin fragments in urine in response to exercise-induced muscle damage. PLoS One 12: e0181623, 2017. https://doi.org/10.1371/journal.pone. 0181623

KANO Y, PADILLA DJ, BEHNKE BJ, HAGEMAN KS, MUSCH TI, POOLE DC: Effects of eccentric exercise on microcirculation and microvascular oxygen pressures in rat spinotrapezius muscle. J Appl Physiol 99: 1516-1522, 2005. https://doi.org/10.1152/japplphysiol.00069.2005

KATZ B: The relation between force and speed in muscular contraction. J Physiol 96: 45-64, 1939. https://doi.org/10.1113/jphysiol.1939.sp003756

KJAER M: Role of Extracellular Matrix in Adaptation of Tendon and Skeletal Muscle to Mechanical Loading. Physiol Rev 84: 649-698, 2004. https://doi.org/10.1152/physrev.00031.2003

KLARLUND PEDERSEN B, STEENSBERG A, SCHJERLING P: Topical review muscle-derived interleukin-6: possible biological effects. J Physiol 536: 329-337, 2001. https://doi.org/10.1111/j.1469-7793.2001.0329c.xd

KOH TJ: Do small heat shock proteins protect skeletal muscle from injury? Exerc Sport Sci Rev 30: 117-121, 2002. https://doi.org/10.1097/00003677-200207000-00005

KORBECKI J, BARANOWSKA-BOSIACKA I, GUTOWSKA I, CHLUBEK D: The effect of reactive oxygen species on the synthesis of prostanoids from arachidonic acid. J Physiol Pharmacol 64: 409-421, 2013.

KRISTIANSEN S, JONES J, HANDBERG A, DOHM GL, RICHTER EA: Eccentric contractions decrease glucose transporter transcription rate, mRNA, and protein in skeletal muscle. Am J Physiol Physiol 272: C1734-C1738, 1997. https://doi.org/10.1152/ajpcell.1997.272.5.C1734

LAAKSONEN MS, KIVELÄ R, KYRÖLÄINEN H, SIPILÄ S, SELÄNNE H, LAUTAMÄKI R, NUUTILA P, KNUUTI J, KALLIOKOSKI KK, KOMI P V.: Effects of exhaustive stretch-shortening cycle exercise on muscle blood flow during exercise. Acta Physiol 186: 261-270, 2006. https://doi.org/10.1111/j.17481716.2006.01532.x

LASTAYO P, MARCUS R, DIBBLE L, FRAJACOMO F, LINDSTEDT S: Eccentric exercise in rehabilitation: safety, feasibility, and application. J Appl Physiol 116: 1426-1434, 2014. https://doi.org/10.1152/japplphysiol.00008.2013 
LASTAYO PC, REICH TE, URQUHART M, HOPPELER H, LINDSTEDT SL: Chronic eccentric exercise: improvements in muscle strength can occur with little demand for oxygen. Am J Physiol 276: R611-5, 1999. https://doi.org/10.1152/ajpregu.1999.276.2.R611

LAURITZEN F, PAULSEN G, RAASTAD T, BERGERSEN LH, OWE SG: Gross ultrastructural changes and necrotic fiber segments in elbow flexor muscles after maximal voluntary eccentric action in humans. J Appl Physiol 107: 1923-1934, 2009. https://doi.org/10.1152/japplphysiol.00148.2009

LAVENDER AP, NOSAKA K: Changes in markers of muscle damage of middle-aged and young men following eccentric exercise of the elbow flexors. J Sci Med Sport 11: 124-131, 2008. https://doi.org/10.1016/j.jsams.2006.11.004

LEMAIRE K, RAVIER MA, SCHRAENEN A, CREEMERS JWM, VAN DE PLAS R, GRANVIK M, VAN LOMMEL L, WAELKENS E, CHIMIENTI F, RUTTER GA, GILON P, IN'T VELD PA, SCHUIT FC: Insulin crystallization depends on zinc transporter ZnT8 expression, but is not required for normal glucose homeostasis in mice. Proc Natl Acad Sci USA 106: 14872-14877, 2009. https://doi.org/10.1073/pnas.0906587106

LEON BM, MADDOX TM: Diabetes and cardiovascular disease: Epidemiology, biological mechanisms, treatment recommendations and future research. World J Diabetes 6: 1246-58, 2015. https://doi.org/10.4239/wjd.v6.i13.1246

LIMA-CABELlO E, CUEVAS MJ, GARATACHEA N, BALDINI M, ALMAR M, GONZÁLEZ-GALLEGO J: Eccentric exercise induces nitric oxide synthase expression through nuclear factor-B modulation in rat skeletal muscle. J Appl Physiol 108: 575-583, 2010. https://doi.org/10.1152/japplphysiol.00816.2009

LINDSAY A, COSTELLO JT: Realising the potential of urine and saliva as diagnostic tools in sport and exercise medicine. Sports Med 47: 11-31, 2017. https://doi.org/10.1007/s40279-016-0558-1

LIU Y, GAMPERT L, NETHING K, STEINACKER JM: Response and function of skeletal muscle heat shock protein 70. Front Biosci 11: 2802-2827, 2006. https://doi.org/10.2741/2011

LYNCH GS, FARY CJ, WILLIAMS DA: Quantitative measurement of resting skeletal muscle $\left[\mathrm{Ca}^{2+}\right]$ i following acute and long-term downhill running exercise in mice. Cell Calcium 22: 373-383, 1997. https://doi.org/10.1016/S0143-4160(97)90022-1

MACALUSO F, ISAACS AW, MYBURGH KH: Preferential type II muscle fiber damage from plyometric exercise. J Athl Train 47: 414-420, 2012. https://doi.org/10.4085/1062-6050-47.4.13

MACINTYRE DL, REID WD, LYSTER DM, SZASZ IJ, MCKENZIE DC: Presence of WBC, decreased strength, and delayed soreness in muscle after eccentric exercise. J Appl Physiol 80: 1006-13, 1996. https://doi.org/10.1152/jappl.1996.80.3.1006

MACINTYRE DL, REID WD, MCKENZIE DC: Delayed Muscle Soreness. Sport Med 20: $24-40,1995$. https://doi.org/10.2165/00007256-199520010-00003

MACKEY AL, BRANDSTETTER S, SCHJERLING P, BOJSEN-MOLLER J, QVORTRUP K, PEDERSEN MM, DOESSING S, KJAER M, MAGNUSSON SP, LANGBERG H: Sequenced response of extracellular matrix deadhesion and fibrotic regulators after muscle damage is involved in protection against future injury in human skeletal muscle. FASEB J 25: 1943-1959, 2011. https://doi.org/10.1096/fj.10-176487

MACPHERSON PCD, SCHORK MA, FAULKNER JA: Contraction-induced injury to single fiber segments from fast and slow muscles of rats by single stretches. Am J Physiol 271: C1438-46, 1996. https://doi.org/10.1152/ajpcell.1996.271.5.C1438

MALM C, NYBERG P, ENGSTRÖM M, SJÖDIN B, LENKEI R, EKBLOM B, LUNDBERG I: Immunological changes in human skeletal muscle and blood after eccentric exercise and multiple biopsies. J Physiol 529: 243-262, 2000. https://doi.org/10.1111/j.1469-7793.2000.00243.x

MALM C: Exercise-induced muscle damage and inflammation: fact or fiction? Acta Physiol Scand 171: 233-239, 2001. https://doi.org/10.1046/j.1365-201x.2001.00825.x

MATHENY W, MERRITT E, ZANNIKOS SV, FARRAR RP, ADAMO ML: Serum IGF-I-deficiency does not prevent compensatory skeletal muscle hypertrophy in resistance exercise. Exp Biol Med 234: 164-170, 2009. https://doi.org/10.3181/0808-RM-251 
MCBRIDE T: Increased depolarization, prolonged recovery and reduced adaptation of the resting membrane potential in aged rat skeletal muscles following eccentric contractions. Mech Ageing Dev 115: 127-138, 2000. https://doi.org/10.1016/S0047-6374(00)00111-1

MCBRIDE TA, STOCKERT BW, GORIN FA, CARLSEN RC: Stretch-activated ion channels contribute to membrane depolarization after eccentric contractions. J Appl Physiol 88: 91-101, 2000. https://doi.org/10.1152/jappl.2000.88.1.91

MCGINLEY C, SHAFAT A, DONNELLY AE: Does antioxidant vitamin supplementation protect against muscle damage? Sport Med 39: 1011-1032, 2009. https://doi.org/10.2165/11317890-000000000-00000

MCHUGH MP: Recent advances in the understanding of the repeated bout effect: The protective effect against muscle damage from a single bout of eccentric exercise. Scand J Med Sci Sport 13: 88-97, 2003. https://doi.org/10.1034/j.1600-0838.2003.02477.x

MCKUNE AJ, SEMPLE SJ, PETERS-FUTRE EM: Acute exercise-induced muscle injury. Biol Sport 29: 3-10, 2012. https://doi.org/10.5604/20831862.978976

MCNEIL PL, KHAKEE R: Disruptions of muscle fiber plasma membranes. Role in exercise-induced damage. Am J Pathol 140: 1097-109, 1992.

MERRY TL, STEINBERG GR, LYNCH GS, MCCONELL GK: Skeletal muscle glucose uptake during contraction is regulated by nitric oxide and ROS independently of AMPK. Am J Physiol Endocrinol Metab 298: 577-585, 2010. https://doi.org/10.1152/ajpendo.00239.2009

MICHAILIDIS Y, KARAGOUNIS LG, TERZIS G, JAMURTAS AZ, SPENGOS K, TSOUKAS D, CHATZINIKOLAOU A, MANDALIDIS D, STEFANETTI RJ, PAPASSOTIRIOU I, ATHANASOPOULOS S, HAWLEY JA, RUSSELL AP, FATOUROS IG: Thiol-based antioxidant supplementation alters human skeletal muscle signaling and attenuates its inflammatory response and recovery after intense eccentric exercise. Am J Clin Nutr 98: 233-245, 2013. https://doi.org/10.3945/ajcn.112.049163

MILANOVIĆ Z, SPORIŠ G, WESTON M: Effectiveness of high-intensity interval training (HIT) and continuous endurance training for $\mathrm{VO}_{2}$ max improvements: A systematic review and meta-analysis of controlled trials. Sport Med 45: 1469-1481, 2015. https://doi.org/10.1007/s40279-015-0365-0

MILLS M: Differential expression of the actin-binding proteins, alpha-actinin-2 and -3, in different species: implications for the evolution of functional redundancy. Hum Mol Genet 10: 1335-1346, 2001. https://doi.org/10.1093/hmg/10.13.1335

MINAHAN C, JOYCE S, BULMER AC, CRONIN N, SABAPATHY S: The influence of estradiol on muscle damage and leg strength after intense eccentric exercise. Eur J Appl Physiol 115: 1493-1500, 2015. https://doi.org/10.1007/s00421-015-3133-9

MORAIS GP, DA ROCHA A, PINTO AP, OLIVEIRA LDC, DE VICENTE LG, FERREIRA GN, DE FREITAS EC, DA SILVA ASR: Uphill running excessive training increases gastrocnemius glycogen content in C57BL/6 mice. Physiol Res 67: 107-115, 2018. https://doi.org/10.33549/physiolres.933614

MORAIS GP, DA ROCHA AL, NEAVE LM, DE LUCAS GA, LEONARD TR, CARVALHO A, DA SILVA ASR, HERZOG W: Chronic uphill and downhill exercise protocols do not lead to sarcomerogenesis in mouse skeletal muscle. J Biomech 98: 109469, 2020. https://doi.org/10.1016/j.jbiomech.2019.109469

MORGAN DL: New insights into the behavior of muscle during active lengthening. Biophys J 57: $209-221$, 1990. https://doi.org/10.1016/S0006-3495(90)82524-8

MORGAN DL, ALLEN DG: Early events in stretch-induced muscle damage. J Appl Physiol 87: 2007-2015, 1999. https://doi.org/10.1152/jappl.1999.87.6.2007

MORTON JP, KAYANI AC, MCARDLE A, DRUST B: The exercise-induced stress response of skeletal muscle, with specific emphasis on humans. Sport Med 39: 643-662, 2009. https://doi.org/10.2165/00007256-200939080$\underline{00003}$

MURPHY RM, DUTKA TL, HORVATH D, BELL JR, DELBRIDGE LM, LAMB GD: Ca ${ }^{2+}$-dependent proteolysis of junctophilin-1 and junctophilin-2 in skeletal and cardiac muscle. J Physiol 591: 719, 2013. https://doi.org/10.1113/jphysiol.2012.243279 
MURTON AJ, CONSTANTIN D, GREENHAFF PL: The involvement of the ubiquitin proteasome system in human skeletal muscle remodelling and atrophy. Biochim Biophys Acta - Mol Basis Dis 1782: 730-743, 2008. https://doi.org/10.1016/j.bbadis.2008.10.011

NAKAMOTO I, ISHIHARA A: Effects of voluntary running exercise on skeletal muscle properties in nonobese rats with type 2 diabetes. Physiol Res 69: 73-84, 2020. https://doi.org/10.33549/physiolres.934178

NOMIYAMA T, IGARASHI Y, TAKA H, MINEKI R, UCHIDA T, OGIHARA T, CHOI JB, UCHINO H, TANAKA Y, MAEGAWA H, KASHIWAGI A, MURAYAMA K, KAWAMORI R, WATADA H: Reduction of insulinstimulated glucose uptake by peroxynitrite is concurrent with tyrosine nitration of insulin receptor substrate- 1 . Biochem Biophys Res Commun 320: 639-647, 2004. https://doi.org/10.1016/j.bbrc.2004.06.019

NOSAKA K, CLARKSON PM: Muscle damage following repeated bouts of high force eccentric exercise. Med Sci Sports Exerc 27: 1263-1269, 1995. https://doi.org/10.1249/00005768-199509000-00005

NOSAKA K, NEWTON M: Difference in the magnitude of muscle damage between maximal and submaximal eccentric loading. J strength Cond Res 16: 202-208, 2002. https://doi.org/10.1519/00124278-200205000-00006

NOSAKA K, NEWTON M, SACCO P: Delayed-onset muscle soreness does not reflect the magnitude of eccentric exercise-induced muscle damage. Scand J Med Sci Sport 12: 337-346, 2002. https://doi.org/10.1034/j.16000838.2002.10178.x

OWENS DJ, TWIST C, COBLEY JN, HOWATSON G, CLOSE GL: Exercise-induced muscle damage: What is it, what causes it and what are the nutritional solutions? Eur J Sport Sci 19: 71-85, 2019. https://doi.org/10.1080/17461391.2018.1505957

PALACIO J, GALDIZ JB, ALVAREZ FJ, OROZCO-LEVI M, LLORETA J, GEA JG: Procion orange tracer dye technique vs. identification of intrafibrillar fibronectin in the assessment of sarcolemmal damage. Eur J Clin Invest 32: 443-447, 2002. https://doi.org/10.1046/j.1365-2362.2002.01005.x

PAPACOSTA E, NASSIS GP: Saliva as a tool for monitoring steroid, peptide and immune markers in sport and exercise scienceJ Sci Med Sport, 2011. https://doi.org/10.1016/j.jsams.2011.03.004

PASCHALIS V, NIKOLAIDIS MG, THEODOROU AA, DELI CK, RASO V, JAMURTAS AZ, GIAKAS G, KOUTEDAKIS Y: The effects of eccentric exercise on muscle function and proprioception of individuals being overweight and underweight. J Strength Cond Res 27: 2542-2551, 2013. https://doi.org/10.1519/JSC.0b013e31827fc9a6

PASCHALIS V, NIKOLAIDIS MG, THEODOROU AA, PANAYIOTOU G, FATOUROS IG, KOUTEDAKIS Y, JAMURTAS AZ: A weekly bout of eccentric exercise is sufficient to induce health-promoting effects. Med Sci Sports Exerc 43: 64-73, 2011. https://doi.org/10.1249/MSS.0b013e3181e91d90

PATEL HP, AL-SHANTI N, DAVIES LC, BARTON SJ, GROUNDS MD, TELLAM RL, STEWART CE, COOPER C, SAYER AA: Lean mass, muscle strength and gene expression in community dwelling older men: findings from the Hertfordshire Sarcopenia Study (HSS). Calcif Tissue Int 95: 308-316, 2014. https://doi.org/10.1007/s00223-014-9894-Z

PAUL AC, ROSENTHAL N: Different modes of hypertrophy in skeletal muscle fibers. J Cell Biol 156: 751-760, 2002. https://doi.org/10.1083/jcb.200105147

PAULSEN G, EGNER IM, DRANGE M, LANGBERG H, BENESTAD HB, FJELD JG, HALLÉN J, RAASTAD T: A COX-2 inhibitor reduces muscle soreness, but does not influence recovery and adaptation after eccentric exercise. Scand J Med Sci Sports 20: e195-e207, 2010. https://doi.org/10.1111/j.1600-0838.2009.00947.x

PAULSEN G, MIKKELSEN UR, RAASTAD T, PEAKE JM: Leucocytes, cytokines and satellite cells: what role do they play in muscle damage and regeneration following eccentric exercise? Exerc Immunol Rev 18: 42-97, 2012.

PEAKE J, NOSAKA K, SUZUKI K: Characterization of inflammatory responses to eccentric exercise in humans. Exerc Immunol Rev 11: 64-85, 2005a.

PEAKE JM, DELLA GATTA P, SUZUKI K, NIEMAN DC: Cytokine expression and secretion by skeletal muscle cells: regulatory mechanisms and exercise effects. Exerc Immunol Rev 21: 8-25, 2015.

PEAKE JM, NEUBAUER O, DELLA GATTA PA, NOSAKA K: Muscle damage and inflammation during recovery from exercise. J Appl Physiol 122: 559-570, 2017a. https://doi.org/10.1152/japplphysiol.00971.2016 
PEAKE JM, NEUBAUER O, WALSH NP, SIMPSON RJ: Recovery of the immune system after exercise. J Appl Physiol 122: 1077-1087, 2017b. https://doi.org/10.1152/japplphysiol.00622.2016

PEAKE JM, SUZUKI K, HORDERN M, WILSON G, NOSAKA K, COOMBES JS: Plasma cytokine changes in relation to exercise intensity and muscle damage. Eur J Appl Physiol 95: 514-521, 2005b. https://doi.org/10.1007/s00421-005-0035-2

PEDERSEN BK: Muscles and their myokines. J Exp Biol 214: 337-346, 2011a. https://doi.org/10.1242/jeb.048074

PEDERSEN BK: Exercise-induced myokines and their role in chronic diseases. Brain Behav Immun 25: 811-816, 2011b. https://doi.org/10.1016/j.bbi.2011.02.010

PEDERSEN BK, ÅKERSTRÖM TCA, NIELSEN AR, FISCHER CP: Role of myokines in exercise and metabolism. J Appl Physiol 103: 1093-1098, 2007. https://doi.org/10.1152/japplphysiol.00080.2007

PEDERSEN BK, FEBBRAIO MA: Muscle as an Endocrine Organ: Focus on Muscle-Derived Interleukin-6. Physiol Rev 88: 1379-1406, 2008. https://doi.org/10.1152/physrev.90100.2007

PEÑAILILLO L, BLAZEVICH A, NUMAZAWA H, NOSAKA K: Rate of force development as a measure of muscle damage. Scand J Med Sci Sports 25: 417-427, 2015. https://doi.org/10.1111/sms.12241

PEÑAILILLO L, GUZMÁN N, CANGAS J, REYES A, ZBINDEN-FONCEA H: Metabolic demand and muscle damage induced by eccentric cycling of knee extensor and flexor muscles. Eur J Sport Sci 17: 179-187, 2017. https://doi.org/10.1080/17461391.2016.1217278

PEREIRA BC, DA ROCHA AL, PINTO AP, PAULI JR, DE MOURA LP, MEKARY RA, DE FREITAS EC, DA SILVA ASR: Excessive training impairs the insulin signal transduction in mice skeletal muscles. J Endocrinol 230: 93-104, 2016a. https://doi.org/10.1530/JOE-16-0063

PEREIRA BC, DA ROCHA AL, PINTO AP, PAULI JR, DE SOUZA CT, CINTRA DE, ROPELLE ER, DE FREITAS EC, ZAGATTO AM, DA SILVA ASR: Excessive eccentric exercise-induced overtraining model leads to endoplasmic reticulum stress in mice skeletal muscles. Life Sci 145: 144-151, $2016 \mathrm{~b}$. https://doi.org/10.1016/j.1fs.2015.12.037

PEREIRA BC, FILHO LAL, ALVES GF, PAULI JR, ROPELLE ER, SOUZA CT, CINTRA DE, SAAD MJA, SILVA ASR: A new overtraining protocol for mice based on downhill running sessions. Clin Exp Pharmacol Physiol 39: 793-798, 2012. https://doi.org/10.1111/j.1440-1681.2012.05728.x

PETROF BJ, SHRAGER JB, STEDMAN HH, KELLY AM, SWEENEY HL: Dystrophin protects the sarcolemma from stresses developed during muscle contraction. Proc Natl Acad Sci 90: 3710-3714, 1993. https://doi.org/10.1073/pnas.90.8.3710

PHILIPPE M, GATTERER H, EDER EM, DZIEN A, SOMAVILLA M, MELMER A, EBENBICHLER C, MÜLLER T, BURTSCHER M: The effects of 3 weeks of uphill and downhill walking on blood lipids and glucose metabolism in pre-diabetic men: A pilot study. J Sport Sci Med 16: 35-43, 2017.

PHILIPPE M, JUNKER G, GATTERER H, MELMER A, BURTSCHER M: Acute effects of concentric and eccentric exercise matched for energy expenditure on glucose metabolism in healthy females: a randomized crossover trial. Springerplus 5, 2016a. https://doi.org/10.1186/s40064-016-3062-z

PHILIPPE M, KRÜSMANN PJ, MERSA L, EDER EM, GATTERER H, MELMER A, EBENBICHLER C, BURTSCHER M: Acute effects of concentric and eccentric exercise on glucose metabolism and Interleukin-6 concentration in healthy males. Biol Sport 33: 153-158, 2016b. https://doi.org/10.5604/20831862.1198634

PIITULAINEN H, BOTTER A, MERLETTI R, AVELA J: Muscle fiber conduction velocity is more affected after eccentric than concentric exercise. Eur J Appl Physiol 111: 261-273, 2011. https://doi.org/10.1007/s00421$\underline{010-1652-y}$

PIRKMAJER S, CHIBALIN A V: Na,K-ATPase regulation in skeletal muscle. Am J Physiol Endocrinol Metab 311: 1-31, 2016. https://doi.org/10.1152/ajpendo.00539.2015

PIZZA FX, KOH TJ, MCGREGOR SJ, BROOKS S V.: Muscle inflammatory cells after passive stretches, isometric contractions, and lengthening contractions. J Appl Physiol 92: 1873-1878, 2002. https://doi.org/10.1152/japplphysiol.01055.2001

PLOUTZ-SNYDER LL, NYREN S, COOPER TG, POTCHEN EJ, MEYER RA: Different effects of exercise and edema onT2 relaxation in skeletal muscle. Magn Reson Med 37: 676-682, 1997. https://doi.org/10.1002/mrm.1910370509 
POWERS SK, NELSON WB, HUDSON MB: Exercise-induced oxidative stress in humans: Cause and consequences. Free Radic Biol Med 51: 942-950, 2011. https://doi.org/10.1016/j.freeradbiomed.2010.12.009

PROSKE U, ALLEN TJ: Damage to skeletal muscle form eccentric exercise. Exerc Sport Sci Rev 33: 98-105, 2005. https://doi.org/10.1097/00003677-200504000-00007

PROSKE U, MORGAN DL: Muscle damage from eccentric exercise: mechanism, mechanical signs, adaptation and clinical applications. J Physiol 537: 333-45, 2001. https://doi.org/10.1111/j.1469-7793.2001.00333.x

QAISAR R, BHASKARAN S, VAN REMMEN H: Muscle fiber type diversification during exercise and regeneration. Free Radic Biol Med 98: 56-67, 2016. https://doi.org/10.1016/j.freeradbiomed.2016.03.025

QAMAR MM, JAVED MS, DOGAR MZUH, BASHARAT A, RASUL A: The mystery behind the exercise-induced muscle damage. Rawal Med J 44: 888-891, 2019. https://doi.org/10.5455/JPMA.301636

RAASTAD T, OWE SG, PAULSEN G, ENNS D, OVERGAARD K, CRAMERI R, KIIL S, BELCASTRO A, BERGERSEN L, HALLÉN J: Changes in calpain activity, muscle structure, and function after eccentric exercise. Med Sci Sport Exerc 42: 86-95, 2010. https://doi.org/10.1249/MSS.0b013e3181ac7afa

RADAK Z, NAITO H, TAYLOR AW, GOTO S: Nitric oxide: Is it the cause of muscle soreness? 26: 89-94, 2012. https://doi.org/10.1016/j.niox.2011.12.005

RENNIE MJ, WACKERHAGE H, SPANGENBURG EE, BOOTH FW: Control of the Size of the Human Muscle Mass. Annu Rev Physiol 66: 799-828, 2004. https://doi.org/10.1146/annurev.physiol.66.052102.134444

RICHTER EA, HARGREAVES M: Exercise, GLUT4, and skeletal muscle glucose uptake. Physiol Rev 93: 993-1017, 2013. https://doi.org/10.1152/physrev.00038.2012

ROBERTS CK, BARNARD RJ, JASMAN A, BALON TW: Acute exercise increases nitric oxide synthase activity in skeletal muscle. Am J Physiol Metab 277: E390-E394, 1999. https://doi.org/10.1152/ajpendo.1999.277.2.E390

ROIG M, O'BRIEN K, KIRK G, MURRAY R, MCKINNON P, SHADGAN B, REID WD: The effects of eccentric versus concentric resistance training on muscle strength and mass in healthy adults: A systematic review with meta-analysis. Br J Sports Med 43: 556-568, 2009. https://doi.org/10.1136/bjsm.2008.051417

RYDER JW, CHIBALIN AV, ZIERATH JR: Intracellular mechanisms underlying increases in glucose uptake in response to insulin or exercise in skeletal muscle. Acta Physiol Scand 171: 249-257, 2001. https://doi.org/10.1046/j.1365-201x.2001.00827.x

SCHOENFELD BJ: Does exercise-induced muscle damage play a role in skeletal muscle hypertrophy? J Strength Cond Res 26: 1441-1453, 2012. https://doi.org/10.1519/JSC.0b013e31824f207e

SCHRAUWEN P, HESSELINK MKC: Oxidative Capacity, Lipotoxicity, and Mitochondrial Damage in Type 2 Diabetes. Diabetes 53: 1412-1417, 2004. https://doi.org/10.2337/diabetes.53.6.1412

SELLMAN JE, DERUISSEAU KC, BETTERS JL, LIRA VA, SOLTOW QA, SELSBY JT, CRISWELL DS: In vivo inhibition of nitric oxide synthase impairs upregulation of contractile protein mRNA in overloaded plantaris muscle. J Appl Physiol 100: 258-265, 2006. https://doi.org/10.1152/japplphysiol.00936.2005

SEMMLER JG: Motor unit activity after eccentric exercise and muscle damage in humans. Acta Physiol 210: 754-767, 2014. https://doi.org/10.1111/apha.12232

SEMMLER JG, TUCKER KJ, ALLEN TJ, PROSKE U: Eccentric exercise increases EMG amplitude and force fluctuations during submaximal contractions of elbow flexor muscles. J Appl Physiol 103: 979-989, 2007. https://doi.org/10.1152/japplphysiol.01310.2006

SERRAVITE DH, PERRY A, JACOBS KA, ADAMS JA, HARRIELL K, SIGNORILE JF: Effect of whole-body periodic acceleration on exercise-induced muscle damage after eccentric exercise. Int J Sports Physiol Perform 9: 985-992, 2014. https://doi.org/10.1123/ijspp.2013-0512

SHARPLES AP, STEWART CE: Myoblast models of skeletal muscle hypertrophy and atrophy. Curr Opin Clin Nutr Metab Care 14: 230-236, 2011. https://doi.org/10.1097/MCO.0b013e3283457ade

SHIMODA-MATSUBAYASHI S, MATSUMINE H, KOBAYASHI T, NAKAGAWA-HATTORI Y, SHIMIZU Y, MIZUNO Y: Structural dimorphism in the mitochondrial targeting sequence in the human manganese superoxide dismutase gene. A predictive evidence for conformational change to influence mitochondrial transport and a study of allelic association in Parkinson's disease. Biochem Biophys Res Commun 226: 561565, 1996. https://doi.org/10.1006/bbrc.1996.1806 
SIM MK, WONG YC, XU XG, LOKE WK: Des-aspartate-angiotensin I attenuates ICAM-1 formation in hydrogen peroxide-treated L6 skeletal muscle cells and soleus muscle of mice subjected to eccentric exercise. Regul Pept 188: 40-45, 2013. https://doi.org/10.1016/j.regpep.2013.12.003

SIRIGULENG, KOIKE T, NATSUME Y, IWAMA S, OSHIDA Y: Effect of prior chronic aerobic exercise on overload-induced skeletal muscle hypertrophy in mice. Physiol Res 67: 765-775, 2018. https://doi.org/10.33549/physiolres.933786

SOMBOONWONG J, TRAISAENG S, SAGUANRUNGSIRIKUL S: Moderate-intensity exercise training elevates serum and pancreatic zinc levels and pancreatic ZnT8 expression in streptozotocin-induced diabetic rats. Life Sci 139: 46-51, 2015. https://doi.org/10.1016/j.1fs.2015.08.008

SORICHTER S, KOLLER A, HAID C, WICKE K, JUDMAIER W, WERNER P, RAAS E: Light concentric exercise and heavy eccentric muscle loading: effects on CK, MRI and markers of inflammation. Int J Sports Med 16: 288-292, 1995. https://doi.org/10.1055/s-2007-973007

SORICHTER S, MAIR J, KOLLER A, GEBERT W, RAMA D, CALZOLARI C, ARTNER-DWORZAK E, PUSCHENDORF B: Skeletal troponin I as a marker of exercise-induced muscle damage. J Appl Physiol 83: 1076-1082, 1997. https://doi.org/10.1152/jappl.1997.83.4.1076

SORICHTER S, MAIR J, KOLLER A, PELSERS MM, PUSCHENDORF B, GLATZ JF: Early assessment of exercise induced skeletal muscle injury using plasma fatty acid binding protein. Br J Sports Med 32: 121-124, 1998. https://doi.org/10.1136/bjsm.32.2.121

SORICHTER S, PUSCHENDORF B, MAIR J: Skeletal muscle injury induced by eccentric muscle action: Muscle proteins as markers of muscle fiber injury. Exerc Immunol Rev 5: 5-21, 1999.

SPANGENBURG EE, MCBRIDE TA: Inhibition of stretch-activated channels during eccentric muscle contraction $\begin{array}{llllllll}\text { attenuates } & \text { p70 } & \text { S6K } & \text { activation. } & \text { J } & \text { Appl } & \text { Physiol 1006 }\end{array}$ https://doi.org/10.1152/japplphysiol.00619.2005

SPROUSE C, GORDISH-DRESSMAN H, ORKUNOGLU-SUER EF, LIPOF JS, MOECKEL-COLE S, PATEL RR, ADHAM K, LARKIN JS, HUBAL MJ, KEARNS AK, CLARKSON PM, THOMPSON PD, ANGELOPOULOS TJ, GORDON PM, MOYNA NM, PESCATELLO LS, VISICH PS, ZOELLER RF, HOFFMAN EP, TOSI LL, DEVANEY JM: SLC30A8 nonsynonymous Variant is associated with recovery following exercise and skeletal muscle size and strength. Diabetes 63: 363-368, 2014. https://doi.org/10.2337/db14-0030

STANFORD KI, GOODYEAR LJ: Exercise and type 2 diabetes: Molecular mechanisms regulating glucose uptake in skeletal muscle. Adv Physiol Educ 38: 308-314, 2014. https://doi.org/10.1152/advan.00080.2014

STARBUCK C, ESTON RG: Exercise-induced muscle damage and the repeated bout effect: evidence for cross transfer. Eur J Appl Physiol 112: 1005-1013, 2012. https://doi.org/10.1007/s00421-011-2053-6

STAUBER WT, CLARKSON PM, FRITZ VK, EVANS WJ: Extracellular matrix disruption and pain after eccentric muscle action. J Appl Physiol 69: 868-874, 1990. https://doi.org/10.1152/jappl.1990.69.3.868

STEENSBERG A, KELLER C, HILLIG T, FRØSIG C, WOJTASZEWSKI JFP, PEDERSEN BK, PILEGAARD H, SANDER M: Nitric oxide production is a proximal signaling event controlling exercise-induced mRNA expression in human skeletal muscle. FASEB J 21: 2683-2694, 2007. https://doi.org/10.1096/fj.06-7477com

STUPKA N, TARNOPOLSKY MA, YARDLEY NJ, PHILLIPS SM: Cellular adaptation to repeated eccentric exercise-induced muscle damage. J Appl Physiol 91: 1669-1678, 2001. https://doi.org/10.1152/jappl.2001.91.4.1669

SYLOW L, KLEINERT M, PEHMØLLER C, PRATS C, CHIU TT, KLIP A, RICHTER EA, JENSEN TE: Akt and Rac1 signaling are jointly required for insulin-stimulated glucose uptake in skeletal muscle and downregulated in insulin resistance. Cell Signal 26: 323-331, 2014a. https://doi.org/10.1016/j.cellsig.2013.11.007

SYLOW L, MØLLER LLV, KLEINERT M, RICHTER EA, JENSEN TE: Stretch-stimulated glucose transport in skeletal muscle is regulated by Rac1. J Physiol 593: 645-656, 2015. https://doi.org/10.1113/jphysiol.2014.284281

SYLOW L, MØLLER LL V., KLEINERT M, RICHTER EA, JENSEN TE: Rac1 - a novel regulator of contractionstimulated glucose uptake in skeletal muscle. Exp Physiol 99: 1574-1580, $2014 \mathrm{~b}$. https://doi.org/10.1113/expphysiol.2014.079194 
SYLOW L, NIELSEN IL, KLEINERT M, MØLLER LLV, PLOUG T, SCHJERLING P, BILAN PJ, KLIP A, JENSEN TE, RICHTER EA: Rac1 governs exercise-stimulated glucose uptake in skeletal muscle through regulation of GLUT4 translocation in mice. J Physiol 594: 4997-5008, 2016. https://doi.org/10.1113/JP272039

SZCZYGLOWSKI MK, ADE CJ, CAMPBELL JA, BLACK CD: The effects of exercise-induced muscle damage on critical torque. Eur J Appl Physiol 117: 2225-2236, 2017. https://doi.org/10.1007/s00421-017-3710-1

TALBOT JA, MORGAN DL: Quantitative analysis of sarcomere non-uniformities in active muscle following a stretch. J Muscle Res Cell Motil 17: 261-268, 1996. https://doi.org/10.1007/BF00124247

TEE JC, BOSCH AN, LAMBERT MI: Metabolic consequences of exercise-induced muscle damage. Sports Med 37: 827-836, 2007. https://doi.org/10.2165/00007256-200737100-00001

TIDBALL JG: Inflammatory processes in muscle injury and repair. Am J Physiol Regul Integr Comp Physiol 288: 345-353, 2005. https://doi.org/10.1152/ajpregu.00454.2004

TIDBALL JG, VILLALTA SA: Regulatory interactions between muscle and the immune system during muscle regeneration. Am J Physiol Integr Comp Physiol 298: R1173-R1187, 2010. https://doi.org/10.1152/ajpregu.00735.2009

TIIDUS PM: Estrogen and HRT promote a proanabolic skeletal muscle environment in older women. J Appl Physiol 107: 1367-1368, 2009. https://doi.org/10.1152/japplphysiol.00991.2009

TIIDUS PM, ENNS DL: Point:Counterpoint: Estrogen and sex do/do not influence post-exercise indexes of muscle damage, inflammation, and repair. J Appl Physiol 106: 1010-1012, 2009. https://doi.org/10.1152/japplphysiol.90848.2008

TORRES R, VASQUES J, DUARTE JA, CABRI JMH: Knee proprioception after exercise-induced muscle damage. Int J Sports Med 31: 410-415, 2010. https://doi.org/10.1055/s-0030-1248285

TORRES SH, DE SANCTIS JB, DE L BRICEÑO M, HERNÁNDEZ N, FINOL HJ: Inflammation and nitric oxide production in skeletal muscle of type 2 diabetic patients. J Endocrinol 181: 419-27, 2004. https://doi.org/10.1677/joe.0.1810419

TUMOVA J, ANDEL M, TRNKA J: Excess of free fatty acids as a cause of metabolic dysfunction in skeletal muscle. Physiol Res 65: 193-207, 2016. https://doi.org/10.33549/physiolres.932993

VAUGHAN D, BROGIOLI M, MAIER T, WHITE A, WALDRON S, RITTWEGER J, TOIGO M, WETTSTEIN J, LACZKO E, FLÜCK M: The Angiotensin Converting Enzyme Insertion/Deletion Polymorphism Modifies Exercise-Induced Muscle Metabolism. PLoS One 11: e0149046, 2016. https://doi.org/10.1371/journal.pone.0149046

VAUGHAN D, HUBER-ABEL FA, GRABER F, HOPPELER H, FLÜCK M: The angiotensin converting enzyme insertion/deletion polymorphism alters the response of muscle energy supply lines to exercise. Eur J Appl Physiol 113: 1719-1729, 2013. https://doi.org/10.1007/s00421-012-2583-6

VELDERS M, DIEL P: How Sex Hormones Promote Skeletal Muscle Regeneration. Sport Med 43: 1089-1100, 2013. https://doi.org/10.1007/s40279-013-0081-6

VENCKUNAS T, SKURVYDAS A, BRAZAITIS M, KAMANDULIS S, SNIECKUS A, MORAN CN: Human alphaactinin-3 genotype association with exercise-induced muscle damage and the repeated-bout effect. Appl Physiol Nutr Metab 37: 1038-1046, 2012. https://doi.org/10.1139/h2012-087

VERBURG E, MURPHY RM, STEPHENSON DG, LAMB GD: Disruption of excitation-contraction coupling and titin by endogenous $\mathrm{Ca} 2+$-activated proteases in toad muscle fibres. J Physiol 564: 775-790, 2005. https://doi.org/10.1113/jphysiol.2004.082180

VERMAAS K, RUNHAAR J: Health-Promoting Effects of Eccentric Exercise. Med Sci Sport Exerc 43: 1808, 2011. https://doi.org/10.1249/MSS.0b013e318221beb1

VINCENT HK, PERCIVAL S, CREASY R, ALEXIS D, SEAY AN, ANN ZL, MACMILLAN M, VINCENT KR: Acute effects of enhanced eccentric and concentric resistance exercise on metabolism and inflammation. J Nov Physiother 4: 200, 2014. https://doi.org/10.4172/2165-7025.1000200

WACKERHAGE H, SCHOENFELD BJ, HAMILTON DL, LEHTI M, HULMI JJ: Stimuli and sensors that initiate skeletal muscle hypertrophy following resistance exercise. J Appl Physiol 126: 30-43, 2019. https://doi.org/10.1152/japplphysiol.00685.2018 
WALLBERG-HENRIKSSON H, CONSTABLE SH, YOUNG DA, HOLLOSZY JO: Glucose transport into rat skeletal muscle: Interaction between exercise and insulin. J Appl Physiol 65: 909-913, 1988. https://doi.org/10.1152/jappl.1988.65.2.909

WALSH LD, HESSE CW, MORGAN DL, PROSKE U: Human forearm position sense after fatigue of elbow flexor muscles. J Physiol 558: 705-715, 2004. https://doi.org/10.1113/jphysiol.2004.062703

WARHOL MJ, SIEGEL AJ, EVANS WJ, SILVERMAN LM: Skeletal muscle injury and repair in marathon runners after competition. Am J Pathol 118: 331-339, 1985.

WARREN GL, INGALLS CP, LOWE DA, ARMSTRONG RB: What mechanisms contribute to the strength loss that occurs during and in the recovery from skeletal muscle injury? J Orthop Sport Phys Ther 32: 58-64, 2002. https://doi.org/10.2519/jospt.2002.32.2.58

WARREN GL, LOWE DA, ARMSTRONG RB: Measurement tools used in the study of eccentric contraction-induced injury. Sport Med 27: 43-59, 1999. https://doi.org/10.2165/00007256-199927010-00004

WARREN GL, LOWE DA, HAYES DA, KARWOSKI CJ, PRIOR BM, ARMSTRONG RB: Excitation failure in eccentric contraction-induced injury of mouse soleus muscle. J Physiol 468: 487-499, 1993. https://doi.org/10.1113/jphysiol.1993.sp019783

WEI Y, CHEN K, WHALEY-CONNELL AT, STUMP CS, IBDAH JA, SOWERS JR: Skeletal muscle insulin resistance: role of inflammatory cytokines and reactive oxygen species. Am J Physiol Integr Comp Physiol 294: R673-R680, 2008. https://doi.org/10.1152/ajpregu.00561.2007

WESTERBLAD H, BRUTON JD, ALLEN DG, LÄNNERGREN J: Functional significance of $\mathrm{Ca}^{2+}$ in long-lasting fatigue of skeletal muscle. Eur J Appl Physiol 83: 166-174, 2000. https://doi.org/10.1007/s004210000275

WHITEHEAD NP, WEERAKKODY NS, GREGORY JE, MORGAN DL, PROSKE U: Changes in passive tension of muscle in humans and animals after eccentric exercise. J Physiol 533: 593-604, 2001. https://doi.org/10.1111/j.1469-7793.2001.0593a.x

WILLIAMS AG, DAY SH, FOLLAND JP, GOHLKE P, DHAMRAIT S, MONTGOMERY HE: Circulating angiotensin converting enzyme activity is correlated with muscle strength. Med Sci Sports Exerc 37: 944-948, 2005.

WISEMAN DA, KALWAT MA, THURMOND DC: Stimulus-induced S-nitrosylation of Syntaxin 4 impacts insulin granule exocytosis. J Biol Chem 286: 16344-16354, 2011. https://doi.org/10.1074/jbc.M110.214031

WRIGHT CR, BROWN EL, DELLA GATTA PA, FATOUROS IG, KARAGOUNIS LG, TERZIS G, MASTORAKOS G, MICHAILIDIS Y, MANDALIDIS D, SPENGOS K, CHATZINIKOLAOU A, METHENITIS S, DRAGANIDIS D, JAMURTAS AZ, RUSSELL AP: Regulation of granulocyte colony-stimulating factor and its receptor in skeletal muscle is dependent upon the type of inflammatory stimulus. J Interf Cytokine Res 35 : 710-719, 2015. https://doi.org/10.1089/jir.2014.0159

YAMIN C, AMIR O, SAGIV M, ATTIAS E, MECKEL Y, EYNON N, SAGIV M, AMIR RE: ACE ID genotype affects blood creatine kinase response to eccentric exercise. J Appl Physiol 103: 2057-2061, 2007. https://doi.org/10.1152/japplphysiol.00867.2007

YAMIN C, MECKEL Y, OLIVEIRA J, DUARTE JA, BEN-ZAKEN S, NEMET D, ELIAKIM A: Genetic aspects of exercise and rhabdomyolysis. Pediatr Endocrinol Rev 11: 400-408, 2014.

YANG SY, GOLDSPINK G: Different roles of the IGF-I Ec peptide (MGF) and mature IGF-I in myoblast proliferation and differentiation. FEBS Lett 522: 156-160, 2002. https://doi.org/10.1016/S0014-5793(02)02918-6

YEUNG EW, BALLARD HJ, BOURREAU JP, ALLEN DG: Intracellular sodium in mammalian muscle fibers after eccentric contractions. J Appl Physiol 94: 2475-2482, 2003. https://doi.org/10.1152/japplphysiol.01128.2002

YEUNG EW, BALNAVE CD, BALLARD HJ, BOURREAU J-P, ALLEN DG: Development of T-tubular vacuoles in eccentrically damaged mouse muscle fibres. J Physiol 540: 581-592, $2002 \mathrm{a}$. https://doi.org/10.1113/jphysiol.2001.013839

YEUNG EW, BOURREAU J-P, ALLEN DG, BALLARD HJ: Effect of eccentric contraction-induced injury on force and intracellular $\mathrm{pH}$ in rat skeletal muscles. J Appl Physiol 92: 93-99, $2002 \mathrm{~b}$. https://doi.org/10.1152/jappl.2002.92.1.93 
YEUNG EW, WHITEHEAD NP, SUCHYNA TM, GOTTLIEB PA, SACHS F, ALLEN DG: Effects of stretchactivated channel blockers on $\left[\mathrm{Ca}^{2+}\right] \mathrm{i}$ and muscle damage in the mdx mouse. J Physiol 562: 367-380, 2005. https://doi.org/10.1113/jphysiol.2004.075275

YIN H, PRICE F, RUDNICKI MA: Satellite cells and the muscle stem cell niche. Physiol Rev 93: 23-67, 2013. https://doi.org/10.1152/physrev.00043.2011

YOUN JH, GULVE EA, HOLLOSZY JO: Calcium stimulates glucose transport in skeletal muscle by a pathway independent of contraction. Am J Physiol - Cell Physiol 260, 1991. https://doi.org/10.1152/ajpcell.1991.260.3.C555

ZANCHI NE, LANCHA AH: Mechanical stimuli of skeletal muscle: implications on mTOR/p70s6k and protein synthesis. Eur J Appl Physiol 102: 253-263, 2008. https://doi.org/10.1007/s00421-007-0588-3

ZHOU Y, LI Y, WANG R: Evaluation of exercise-induced muscle damage by surface electromyography. J Electromyogr Kinesiol 21: 356-362, 2011. https://doi.org/10.1016/j.jelekin.2010.09.009

ZIERATH JR: Invited Review: Exercise training-induced changes in insulin signaling in skeletal muscle. J Appl Physiol 93: 773-781, 2002. https://doi.org/10.1152/japplphysiol.00126.2002 